\title{
Overexpressing Temperature-Sensitive Dynamin Decelerates Phototransduction and Bundles Microtubules in Drosophila Photoreceptors
}

\author{
Paloma T. Gonzalez-Bellido, ${ }^{1}$ Trevor J. Wardill, ${ }^{1}$ Ripsik Kostyleva, ${ }^{2}$ Ian A. Meinertzhagen, ${ }^{2}$ and Mikko Juusola ${ }^{1,3}$ \\ ${ }^{1}$ Department of Biomedical Science, University of Sheffield, Sheffield S10 2TN, United Kingdom, ${ }^{2}$ Department of Psychology and Neuroscience, Dalhousie \\ University, Halifax, Nova Scotia 3BH 4J1, Canada, and ${ }^{3}$ State Key Laboratory of Cognitive Neuroscience, Beijing Normal University, Beijing 100875, China
}

\begin{abstract}
shibire $^{\mathrm{ts} 1}$, a temperature-sensitive mutation of the Drosophila gene encoding a Dynamin orthologue, blocks vesicle endocytosis and thus synaptic transmission, at elevated, or restrictive temperatures. By targeted Gal4 expression, UAS-shibire ${ }^{\text {ts } 1}$ has been used to dissect neuronal circuits. We investigated the effects of UAS-shibire ${ }^{\text {ts } 1}$ overexpression in Drosophila photoreceptors at permissive $\left(19^{\circ} \mathrm{C}\right)$ and restrictive $\left(31^{\circ} \mathrm{C}\right)$ temperatures. At $19^{\circ} \mathrm{C}$, overexpression of UAS-shi ${ }^{\text {tsl }}$ causes decelerated phototransduction and reduced neurotransmitter release. This phenotype is exacerbated with dark adaptation, age and in white mutants. Photoreceptors overexpressing UASshibire $^{\text {ts } 1}$ contain terminals with widespread vacuolated mitochondria, reduced numbers of vesicles and bundled microtubules. Immuno-electron microscopy reveals that the latter are dynamin coated. Further, the microtubule phenotype is not restricted to photoreceptors, as UAS-shibire ${ }^{\text {tsl }}$ overexpression in lamina cells also bundles microtubules. We conclude that dynamin has multiple functions that are interrupted by UAS-shibire ${ }^{\text {ts } 1}$ overexpression in Drosophila photoreceptors, destabilizing their neural communication irreversibly at previously reported permissive temperatures.
\end{abstract}

\section{Introduction}

The fly orthologue of Dynamin is encoded by shibire (Chen et al., 1991), a GTPase involved in endocytosis (van der Bliek and Meyerowrtz, 1991; Damke et al., 1994). Under previously tested conditions, the temperature-sensitive allele shibire ${ }^{\text {tsl }}\left(s h i^{\text {tsl }}\right)$ allows normal endocytosis to occur at temperatures $<22^{\circ} \mathrm{C}$, but prevents membrane retrieval at temperatures exceeding $30^{\circ} \mathrm{C}$, leading to reduced neurotransmitter release and synaptic blockade (Kosaka and Ikeda, 1983). Overexpression of $s i^{\text {tsl }^{\text {1 }}}$ (Kitamoto, 2001) using the Gal4/UAS system (Brand and Perrimon, 1993) allows targeted temperature-dependent blockade of synaptic transmission within the Drosophila nervous system (for a review see: Duffy, 2002). Hence, the contribution of individual neurons to identified circuits can be assessed (Luo et al., 2008), such as

\footnotetext{
Received June 17, 2009; revised Aug. 28, 2009; accepted Sept. 22, 2009.

This work was funded by the University of Sheffield, Biotechnology and Biological Sciences Research Counci (BBF0120711 and BBD0019001 to M.J.), Gatsby Charitable Foundation (GAT2839 to M.J.), the Royal Society (UF991042 to M.J.), and the National Eye Institute of the National Institutes of Health (EY-03592 to I.A.M.). We thank M. Ramaswami for the anti-dynamin primary antibody, A. Whitworth and W. Marcotti for discussions, J. A. Borycz for help with immunolabeling. P. Li, Z. Lu, and C. Hill for assistance with EM, and R. C. Hardie, L. C. Griffith, E. Buchner, and T. Kitamoto for fly stocks. P.T.G.-B., T.J.W., and M.J. conceived and designed the experiments. P.T.G.-B. and T.J.W. undertook the fly crossing. P.T.G.-B. performed the immuno-EM, ERGs, intracellular experiments, and analysis. P.T.G.-B. and R.K. performed EM. M.J. wrote the software for stimulation, acquisition, and analysis. M.J. designed the experimental set-ups, and M.J. and T.W. constructed them. P.T.G.-B., T.J.W., M.J., and I.A.M. cowrote the paper.

Correspondence should be addressed to either of the following: Mikko Juusola, Department of Biomedical Science, University of Sheffield, Sheffield S10 2TN, UK; E-mail: m.juusola@sheffield.ac.uk; or lan A. Meinertzhagen, Department of Psychology and Neuroscience, Dalhousie University, Halifax, NS 3BH 4J1, Canada, E-mail: iam@dal.ca. DOI:10.1523/JNEUROSC1.2873-09.2009

Copyright $\odot 2009$ Society for Neuroscience ～0270-6474/09/2914199-12\$15.00/0
}

those involved in color (Gao et al., 2008) or motion perception (Rister et al., 2007).

Temperature-dependent activation of UAS-shits1 was originally studied in Drosophila photoreceptors (Kitamoto, 2001), from which the continuous release (Zheng et al., 2006) of histamine (Hardie, 1987; Sarthy, 1991), to the large monopolar cells (LMC)s (Zheng et al., 2006) is blocked by mutant $s h i^{\text {tsl }}$ at restrictive temperatures. In an electroretinogram (ERG), the eye's field potential response to a light pulse (Heisenberg, 1971), such blockade is apparent by the lack of "On"- and "Off"-transients (Zheng et al., 2006), reported by Coombe (1986) to derive from the LMCs. The permissive $\left(18^{\circ} \mathrm{C}\right)$ and restrictive $\left(31^{\circ} \mathrm{C}\right)$ temperatures for $s h i^{\text {tsl }}$ action, originally defined from their effects on the ERG of homozygous mutant flies (Chen and Stark, 1993), have been confirmed for the UAS-shits ${ }^{\text {tsl }}$ transgene by recording the ERGs of light-adapted flies overexpressing UAS-shits1 in their photoreceptors (Kitamoto, 2001).

Other variables may also affect photoreceptors overexpressing UAS-shits1 . For example, light exposure increases endocytosis and membrane turnover in fly photoreceptors (Stark et al., 1988; Bähner et al., 2002; Kosloff et al., 2003; Chorna-Ornan et al., 2005; Frechter et al., 2007; Han et al., 2007). In addition, aging reduces the time needed for synaptic blockade (Beramendi et al., 2007) and the eye marker gene, white, interacts with $s h i^{\text {ts } 1}$ action (Chen and Stark, 1993). A study controlling for these factors in flies overexpressing shibire ${ }^{\text {tsl }}$ has hitherto been lacking and should reveal additional functions of dynamin. For example, dynamin may act in vivo as a microtubule-associated protein (MAP), an interaction previously demonstrated biochemically (Shpetner and Vallee, 1989). 
To address dynamin function in vivo, we examine how interactions between light exposure, temperature, genetic background and age affect the synaptic output of outer photoreceptors (R1-R6) overexpressing UAS-shit ${ }^{\text {ts1 }}$. To evaluate changes in neurotransmission, we compare the ERGs. These results are then related to changes in phototransduction, recorded intracellularly through light-evoked voltage responses, and to changes in ultrastructure using electron microscopy (EM). We show that at $19^{\circ} \mathrm{C}$, photoreceptors overexpressing UAS-shis ${ }^{\text {ts }}$ have decelerated phototransduction and compromised neurotransmission, both after dark adaptation and in older flies. At $19^{\circ} \mathrm{C}$, photoreceptor terminals contain fewer vesicles, vacuolated mitochondria typical of apoptosis and bundled microtubules decorated with dynamin. These changes reveal the outcome of overexpressing a temperaturesensitive form of dynamin that is functionally impaired even at a permissive temperature of $19^{\circ} \mathrm{C}$.

\section{Materials and Methods}

Fly stocks. The reporter line UAS-shi ${ }^{\text {ts1 }}$ was provided by Dr. Toshihiro Kitamoto (University of Iowa); Canton-S (wild-type), $w^{1118}$ (here referred to simply as white), Rh1-Gal4, and GMR-Gal4 were acquired from the Bloomington Stock Center. MJ85b-Gal4 was a gift from Prof. Leslie C. Griffith (Brandeis University, Waltham, MA), and $h d c^{J K 910}$ flies were from Prof. Erich Buchner (Julius-Maximilians-Universität, Würzburg, Germany). Flies were raised at $18^{\circ} \mathrm{C}$ in a $12 \mathrm{~h}$ dark-light cycle. Female flies were used for all experiments.

UAS-shi ${ }^{t s I}$ overexpression in photoreceptors. We used the UAS/Gal4 system (Brand and Perrimon, 1993) to overexpress UAS-shit ${ }^{\text {ts1 }}$ and dominate wild-type Dynamin function by the mutant temperature-sensitive form of the protein. The driver Rh1-Gal4 was chosen to ensure that UAS-shit ${ }^{\text {ts } 1}$ was expressed solely in photoreceptors R1-R6. $R h 1-$ Gal4 is expressed only in later stages of pupal development of R1-R6 (Kumar and Ready, 1995). Given the weak expression of Rh1-Gal4, we generated homozygous flies for both the UAS-shits and Rh1-Gal4 insertions, and reared them at the permissive temperature, $18^{\circ} \mathrm{C}$. Two different types of homozygous Rh1-shits1 flies were used, having either the wild-type eye color $\left(w^{+}\right)$, or the white mutation $\left(w^{1118}\right)$. In addition, we used GMRGal4, which is strongly expressed in all eight photoreceptors, R1-R8, as well as in the supporting cells in the eye imaginal disc (Freeman, 1996). GMR-Gal4 expression, which starts much earlier than Rh1Gal4 expression, can induce a rough-eye phenotype in homozygous flies when reared at $>23^{\circ} \mathrm{C}$ (Kramer and Staveley, 2003). To prevent a rough-eye phenotype and preserve the normal optics of the compound eyes, we used only heterozygous +; GMR-Gal4/+; UAS$s h i^{\text {ts } 1} /+$ flies reared at $18^{\circ} \mathrm{C}$.

Fly crosses. white Rh1-shi ${ }^{\text {ts1 }}$ flies with insertions of $\mathrm{P}\left(r y^{+}, R h 1-\mathrm{Gal} 4\right)$ and $\mathrm{P}\left(w^{+}, \mathrm{UAS}-s h i^{\text {tsl }}\right)$ on chromosomes 2 and 3, respectively, were generated by crossing each insertion line to a white double balancer stock (white; If/CyO; MKRS/TM6b) over two generations, to produce white; Rh1-Gal4/CyO; MKRS/TM6b and white; If/CyO; UAS-shi ${ }^{\text {ts1 }} / \mathrm{TM} 6 \mathrm{~b}$ stocks. These stocks were then crossed to each other to produce a balanced $R h 1-s h i^{\text {tsl }}$ stock carrying both insertions (white; Rh1-Gal4/ CyO; UAS-shits1/TM6b). To exchange the X chromosome to a wild type, a Canton-S double balancer stock was used over two generations. Rh1-Gal4 stock with a Canton-S background was produced as a control line using our Canton-S balancer stock (+; Gla/CyO; +). To gauge the expression levels of UAS-shi ${ }^{\text {ts1 }}$, our balanced stock was further crossed to either Canton-S, UAS-shits1 stock or Canton-S background Rh1-Gal4 stock. Notably, homozygous $R h 1-s h i^{\text {ts1 }}$ flies emerged in a proportion less than the Mendelian ratio predicted $(10 \%$ instead of $25 \%$ ).

GMR-Gal4/+; UAS-shits1 $/+$ flies with a Canton-S background and insertions of $\mathrm{P}\left(w^{+}, G M R-G a l 4\right)$ and $\mathrm{P}\left(w^{+}, \mathrm{UAS}-\right.$ sh $\left.^{{ }^{\text {ts } 1}}\right)$ on chromosomes 2 and 3, respectively, were generated by crossing each insertion line to a Canton-S double balancer stock (+; If/CyO; MKRS/TM6b) over two generations to produce +; GMR-Gal4/CyO; MKRS/TM6b and +; If/CyO; UAS-shits1 $/$ TM6b stocks. These stocks were then crossed to each other to produce a balanced GMR-shitsl stock carrying both insertions ( + ; GMR-Gal4/CyO; UAS-shi ${ }^{\text {tsl }} / \mathrm{TM} 6 \mathrm{~b}$ ). These flies where then crossed in turn to Canton-S to produce +; GMR-Gal4/+; $\mathrm{UAS}-\mathrm{shi}^{\mathrm{ts} 1} /+$ for testing. A GMR-Gal4 stock with a Canton-S background was produced as a control line using our Canton-S balancer stock $(+; \mathrm{Gla} / \mathrm{CyO} ;+)$.

$M j 85 b$-shits ${ }^{\text {ts }}$ flies with a Canton-S background and insertions of $\mathrm{P}\left(w^{+}\right.$, Mj85b-Gal4 $)$and $\mathrm{P}\left(w^{+}, \mathrm{UAS}-\right.$ shi $\left.^{\mathrm{tsl}}\right)$ on chromosomes 1 and 2, respectively, were generated by crossing each insertion line to a Canton-S double balancer stock (FM6/FM7 h; If/CyO) over two generations to produce Mj85b-Gal4/FM7 h; If/CyO and FM6/FM7 h; UAS-shit ${ }^{\text {ts1 }} / \mathrm{CyO}$ stocks. These stocks were then crossed to each other to produce a balanced $M j 85 b$-shits1 stock carrying both insertions (Mj85b-Gal4/FM7 h; UAS-shi $\left.{ }^{\mathrm{ts} 1} / \mathrm{CyO}\right)$.

ERGs. Flies were mounted inside a copper cone and their temperature controlled by a Peltier element (Juusola and Hardie, 2001). To test the effects of light history and temperature on neurotransmission, three experiments were undertaken (supplemental Fig. S1, available at www. jneurosci.org as supplemental material). The adaptation periods at $19^{\circ} \mathrm{C}$ were set at $30 \mathrm{~min}$ because although long-term dark adaptation, measured as the percentage of G-protein translocated to the rhabdomere membrane (Frechter et al., 2007), takes up to 2 h (Kosloff et al., 2003; Cronin et al., 2004), morphological changes related to dark adaptation are readily visible after $30 \mathrm{~min}$ (Kosloff et al., 2003). In contrast, the restrictive period at $31^{\circ} \mathrm{C}$ was kept to $10 \mathrm{~min}$, as this has previously been shown sufficient to block neurotransmission in flies overexpressing UAS-shi ${ }^{\text {tsl }}$ (Kitamoto, 2001). The reference electrode was placed in the ocelli, while a blunt recording electrode was placed on the stimulated eye. Both electrodes were borosilicate glass, filled with fly Ringers. The software and electrophysiology setup were as previously reported (Juusola and Hardie, 2001).

$E R G$ analysis. The influence of fast light adaptation meant that all flies kept in darkness for 30 min displayed "On"-transient sizes in traces 1-4 significantly different from each other and from the rest of the recorded traces (data not shown). It is possible that shibire ${ }^{\text {tsl }}$ flies might release neurotransmitter only in the first traces because of the stimulationdependent depletion of the synaptic vesicle pool (Delgado et al., 2000). Therefore, only traces 5-10 were used to obtain a representative figure for each fly or condition. The three main components of an ERG were quantified: the "On"- and "Off"-transients, corresponding to fast response waveforms of lamina cells — claimed to be LMCs (Coombe, 1986), and most likely amacrine cells that share the same histamine receptor (Zheng et al., 2006; Pantazis et al., 2008), and the slower photoreceptor component (Heisenberg, 1971; Coombe and Heisenberg, 1986). Both photoreceptors and LMCs respond to the inputs continuously, because of the tonic graded-potential synapses (feedforward and feedback) that link them (Juusola et al., 1995; Uusitalo et al., 1995a; Zheng et al., 2006). Photoreceptors hyperpolarize and the LMCs depolarize the ERG waveform in a push-pull relationship. For bright stimuli, LMC output adapts rapidly (Juusola et al., 1995) so that only their transients overcome the large photoreceptor component. Nonetheless, the size of the photoreceptor component is further reduced by the residual sustained component in the LMC responses.

For each fly strain, $6(n)$ flies were tested. For each genotype or treatment the mean and SEM were calculated, and a Student's $t$ test with a Bonferroni correction was conducted. The shapes of the photoreceptor response were analyzed by normalizing the ERGs at $1.78 \mathrm{~s}$, the time chosen as the first point of the sustained component in dark-adapted transgenic lines, after the initial hyperpolarization of the ERG. The amplitude of the ERG at this time point is not significantly different from controls. This is important because normalizing ERG at points with marked differences in the absolute amplitude of the photoreceptor response could influence other dynamics, which in turn could be reflected in the shape of the ERG. The mean of all normalized ERGs for each genotype is shown, the SEM was omitted for clarity. The data acquisition and stimulus protocols were executed under Matlab (Mathworks: Natick, MA), using custom-written soft- 


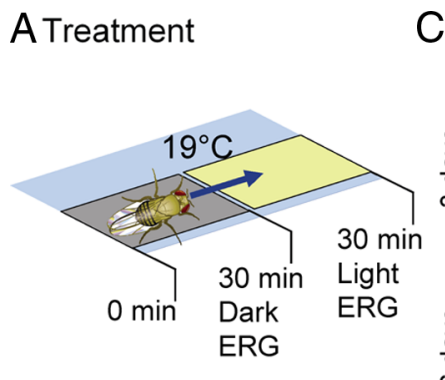

Dark adaptation

Light adaptation

\section{BERG and stimulus}

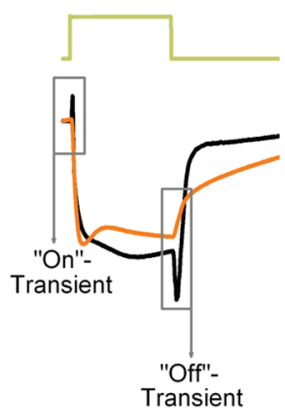

\section{C "On"-transients}
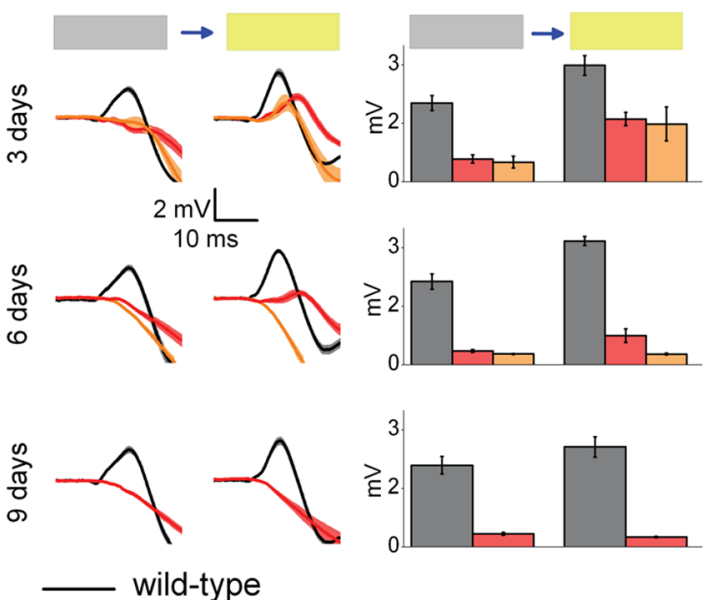

Rh1-shi ${ }^{\text {ts } 1}$ white Rh1-shi ${ }^{\text {ts1 }}$

D"Off"-transients
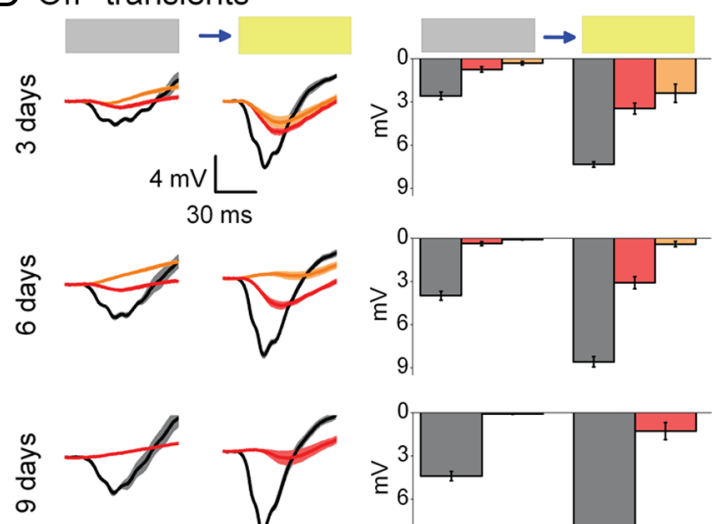

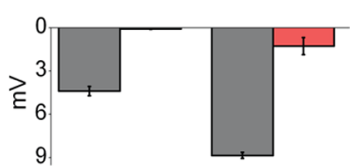

Figure 1. Rh1-shits ${ }^{\text {ts }}$ photoreceptor output depends on light history at $19^{\circ} \mathrm{C}$. $A$, Dark adaptation (30 min) followed by light adaptation ( $30 \mathrm{~min}$ ) at $19^{\circ} \mathrm{C} . \boldsymbol{B}$, ERGs were recorded $(700 \mathrm{~ms}$ stimulus) after each adaptation. Traces are from dark-adapted flies and 6 d posteclosion. $\boldsymbol{C}, \boldsymbol{D}$, The amplitude of "On"-transients $(\boldsymbol{C})$ and "Off"-transients $(\boldsymbol{D})$ quantified for wild type (black), Rh 1 -shi ts $^{\text {1 }}$ (red), and white Rh1-shi ${ }^{\text {ts1 }}$ (orange). Mean \pm SEM is shown in traces and histograms with $n=6$ for each group. Age refers to days posteclosion.

ware. Origin software (OriginLab) was used for the data analysis and plotting.

Light stimulus. To ensure a uniform and reproducible stimulation of the eye, the light source was composed of a matrix of $100(10 \times 10)$ white $3 \mathrm{~mm}$ light-emitting diodes (LEDs) (Nichia LEDs NSPW500BS, 15,500 mcd, $20^{\circ}$ half-width). The overall stimulus illuminance was 5.92 lumen/ $\mathrm{cm}^{2}$. The stimulus was composed of $50 \mathrm{~ms}$ of darkness, $700 \mathrm{~ms}$ of light, followed by $1250 \mathrm{~ms}$ of darkness. This cycle was flashed 10 times in consecutive square-wave pulses, the stimulus used to test the visual response after each adaptation period in each experiment (Fig. 1A). The stimulus-evoked saturating peak responses without being compromised by a prolonged depolarizing afterpotential, as measured by intracellular recordings in wild-type photoreceptors. Here, the responses followed typical adaptation dynamics, seen commonly in bright-light pulse experiments (supplemental Fig. S1, available at www.jneurosci.org as supplemental material). The photoreceptor sensitivity (peak response) first declined and then recovered during subsequent stimulation, indicating that phototransduction maintained responsiveness throughout the experimental protocol.

Intracellular recordings from photoreceptors in vivo. The setup and preparation were established as previously reported (Juusola and Hardie, 2001). Briefly, a hole of $\sim 4 \times 4$ ommatidia was made on the cuticle of the left eye (supplemental Fig. S5, available at www.jneurosci.org as supplemental material) to allow insertion of a sharp quartz electrode (>95

$\mathrm{M} \Omega$ ), which was filled with $3 \mathrm{~m} \mathrm{KCl}$. A reference electrode, which was placed inside the head capsule close to the ocelli, was filled with fly Ringer (Juusola and Hardie, 2001). Cells were selected with a resting potential below $-60 \mathrm{mV}$ and the point light source was placed to maximize the response. The light source comprised of a single high-power LED (Seoul Z-Power LED P4 star, white, 100 lumens), mounted on a cardan arm system and projected by a lens through a pinhole (subtended angle $0.7^{\circ}$ ) and driven by an OptoLED (Cairn Research Ltd). Flies were dark-adapted for a minimum of $20 \mathrm{~min}$ and then stimulated with either a short ( $10 \mathrm{~ms}$ ) or a long light pulse (700 $\mathrm{ms}$ ) and voltage responses of single photoreceptors recorded. See ERG analysis for equipment and software used.

$E M$. For the retina, flies were adapted to room lighting before fixation. For the photoreceptor terminals in the lamina, we replicated the conditions used in Figure 1. Flies were dark-adapted for $30 \mathrm{~min}$. Following this, half of the flies were dissected and fixed using only red light. The rest of the flies were exposed to intense white light for $30 \mathrm{~min}$ and then dissected and fixed in the light. For this experiment, the temperature was held at $17 \pm 1^{\circ} \mathrm{C}$. The dissection, fixation and embedding protocols for all EM observations have been described previously (Meinertzhagen and O'Neil, 1991; Meinertzhagen, 1996). Serial $60 \mathrm{~nm} \mathrm{sec-}$ tions were stained with uranyl acetate and lead citrate and examined at $80 \mathrm{kV}$ in a Philips Tecnai 12 electron microscope. Images were captured with a Kodak Megaview II digital camera, by using Analy-SIS software (SIS). For the vesicle counts, we sampled 3 flies for each condition tested (dark/light, age, genotype), and counted 15 terminals from each fly. For the microtubule counts, we counted profiles in either 28 terminals from 6 flies that were $3 \mathrm{~d}$ posteclosion or in 26 terminals from 6 flies that were $9 \mathrm{~d}$ posteclosion.

EM immunolabeling. Tissue samples prepared as previously reported (Meinertzhagen, 1996) were fixed for EM in a 3\% formaldehyde, $0.25 \%$ glutaraldehyde mixture in $0.1 \mathrm{M}$ phosphate buffer (PB) (pH7.2) as reported (Yasuhara et al., 2000). Sections 50-60 nm thick were collected on nickel grids covered with $0.25 \%$ Pioloform dissolved in chloroform. The postembedding immunogold grid labeling protocol was as previously reported (Goode et al., 2004), but antigen unmasking and silver enhancement were omitted. Primary antibody (affinity-purified Ab 2074), a generous gift from Prof. Mani Ramaswami (Trinity College, Dublin, Ireland), was used at a 1:20 dilution. The Ab 2074 rabbit antiserum was raised against a purified recombinant fusion protein generated by fusing the maltose-binding protein (MBP) to a $66 \mathrm{kDa}$ fragment of Drosophila dynamin lacking the N-terminal 241 aa (lacking the GTP-binding domain) (Estes et al., 1996). Specificity has been shown by Estes et al. (1996) through Western blot and labeling at the Drosophila neuromuscular junction. Secondary antibody [10 nm gold-conjugated goat anti-rabbit IgG $(\mathrm{H}+\mathrm{L}): 10$, BB International] was used at a dilution of 1:20. Labeled grids were stained with aqueous uranyl acetate and viewed as above to detect the subcellular localization of gold particles.

\section{Results}

To characterize how UAS-shits ${ }^{\text {ts1 }}$ overexpression in R1-R6 photoreceptors influences their synaptic output, we quantified neurotransmission and light-evoked photoreceptor response, while 
controlling light exposure, temperature, age and eye color. We characterized how these factors affect the photoreceptors' output to their postsynaptic interneurons in the lamina (Hardie, 1989; Gengs et al., 2002; Zheng et al., 2006; Pantazis et al., 2008). We investigated how the light-evoked response influences the slow component of the ERG, and how this in turn affects interpretation of neurotransmission dynamics. Finally, we linked the physiological changes, induced by UAS-shits ${ }^{\text {t }}$, to the ultrastructure of photoreceptors.

\section{Rh1-shi ${ }^{\text {ts1 }}$ photoreceptor output depends on light history at $19^{\circ} \mathrm{C}$}

To investigate how light exposure affects neurotransmission at permissive temperatures $\left(19^{\circ} \mathrm{C}\right)$, we examined Drosophila which overexpress $s h i^{\text {ts1 }}$ in R1-R6. To overexpress $s h i^{\text {tsl }}$ we used Rh1-Gal4, which uses the ninaE promoter (O'Tousa et al., 1985). We refer to their targeted expression of $s h i^{\text {tsl }}$ as $R h 1-s h i^{\text {tsl }}$. We first examined $R h 1-s h i^{\text {tsl }}$ photoreceptors darkadapted for $30 \mathrm{~min}$, followed by exposure to intense white light for $30 \mathrm{~min}$ (Fig. 1A; supplemental Fig. S1, available at www. jneurosci.org as supplemental material), termed light adaptation in our protocol. After each adaptation, we recorded ERGs from wild-type, $R h 1-s h i^{\text {tsl }}$ and white Rh1$s h i^{\text {ts1 }}$ flies to volleys of 700-ms-long pulses of intense white light (see Materials and Methods for light stimulus) (Fig. $1 B$ ). The size of the "On"- and "Off"-transients, which reflect transmission to the lamina, were then compared after dark and light adaptation at 3, 6, and 9 d posteclosion (Fig. 1C,D).

\section{Dark adaptation reduces synaptic transmission}

At a permissive temperature of $19^{\circ} \mathrm{C}, R h 1-s h i^{\text {tsl }}$ flies were predicted to exhibit ERG responses comparable to wild type (Kitamoto, 2001). Instead, we found that $30 \mathrm{~min}$ of dark adaptation strongly suppressed neurotransmission of $R h 1-s h i^{\text {ts } 1}$ flies (Fig. $1 C, D$ ), in which transients were either missing or very small $(<10 \%$ of the wild type). Dark adaptation affected ERG transients even when a different Gal4-line was used, as seen in +; GMRGal4/+; UAS-shi ${ }^{\text {ts1 } /+~ f l i e s ~(s u p p l e m e n t a l ~ F i g . ~ S 2, ~ a v a i l a b l e ~ a t ~}$ www.jneurosci.org as supplemental material; GMR expressed in R1-R8). After dark adaptation, the ERGs of $s h i^{\text {ts1 }}$ mutants also displayed reduced transient amplitudes (supplemental Fig. S2, available at www.jneurosci.org as supplemental material).

\section{Increased age also reduces synaptic transmission}

The impairment in transmission after dark adaptation worsened with age, seen as a progressive decrease in transient size between 3 and $9 \mathrm{~d}$ posteclosion. Dark adaptation affected white $R h 1-s h i^{\text {tsl }}$ photoreceptors most severely (Fig. 1C,D). Thus, although all tested flies overexpressing UAS-shis ${ }^{\text {ts }}$ displayed a similar phenotype, the level of impairment in their synaptic transmission depended on the eye color and age. posteclosion.

\section{C "On"-transients}
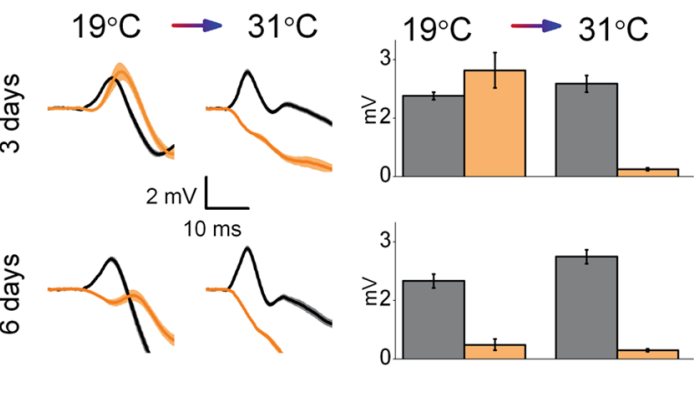

wild-type white Rh1-shits

\section{D "Off"-transients}
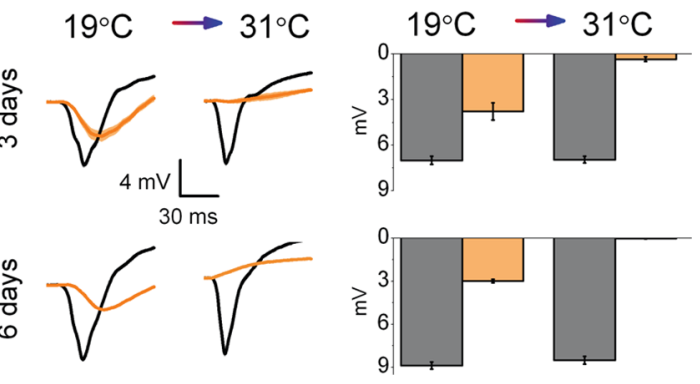

Figure 2. Temperature shift in light-adapted $R h 1-$ shi $i^{\text {ts } 1}$ photoreceptors. $\boldsymbol{A}$, Light adaptation $(30 \mathrm{~min})$ at $19^{\circ} \mathrm{C}$ before light adaptation ( $10 \mathrm{~min}$ ) at $31^{\circ} \mathrm{C}$. $\boldsymbol{B}$, ERGs were recorded ( $700 \mathrm{~ms}$ stimulus) after each adaptation. Traces are from light-adapted flies at $19^{\circ} \mathrm{C}$ and $6 \mathrm{~d}$ posteclosion. $\boldsymbol{C}, \boldsymbol{D}$, The amplitude of "On"-transients $(\boldsymbol{C})$ and "Off"-transients $(\boldsymbol{D})$ quantified for wild type (black) and white Rh1-shit ${ }^{\text {ts1 }}$ (orange). Mean \pm SEM is shown in traces and histograms with $n=6$ for each group. Age refers to days

Light adaptation aids synaptic functions

After dark adaptation, subsequent light helped to restore synaptic function in $R h 1-s h i^{\text {tsl }}$ photoreceptors, seen as the partial return of ERG transients (Fig. 1C,D). Nevertheless, recovery in transmission appeared to be absent at $9 \mathrm{~d}$ posteclosion, revealing ageassociated impairment. These findings suggest that at $19^{\circ} \mathrm{C}$ : (1) dark adaptation of $R h 1-s h i^{\text {ts } 1}$ disrupts the functionality of dynamin-dependent endocytosis that is required to maintain normal synaptic throughput; (2) the underlying mechanisms for the decline in their transmission are similar in all the tested genotypes; and (3) light adaptation partially reverses this phenotype, but only at $3 \mathrm{~d}$ posteclosion, not in older flies.

Temperature shift in light-adapted $R h 1-s h i^{\text {ts } 1}$ photoreceptors Insofar as the transmission defects seen after dark adaptation in $R h 1-s h i^{\text {ts } 1}$ photoreceptors were alleviated by a brief exposure to light, prolonged light adaptation should further improve synaptic transmission. To test this hypothesis and investigate whether synaptic transmission in photoreceptors that overexpress UAS$s h i^{\text {tsl }}$ could be blocked by warming, as shown previously (Kitamoto, 2001), light-adapted flies were exposed to a temperature shift (Fig. 2A). We exposed 3 and $6 \mathrm{~d}$ posteclosion wild type and white $R h 1-s h i^{\text {tsl }}$ (previously kept under bright light for $3 \mathrm{~h}$ ) to a $30 \mathrm{~min}$ period of adaptation to intense white light at $19^{\circ} \mathrm{C}$ followed by 10 min of light at $31^{\circ} \mathrm{C}$. The ability to support synaptic transmission was examined before $\left(19^{\circ} \mathrm{C}\right)$ and after warming $\left(31^{\circ} \mathrm{C}\right)$ by turning off the adapting light momentarily before delivering $700 \mathrm{~ms}$ pulses of intense white light (Fig. $2 B$, supplemental Fig. S1 $B$, available at www.jneurosci.org as supplemental material). 

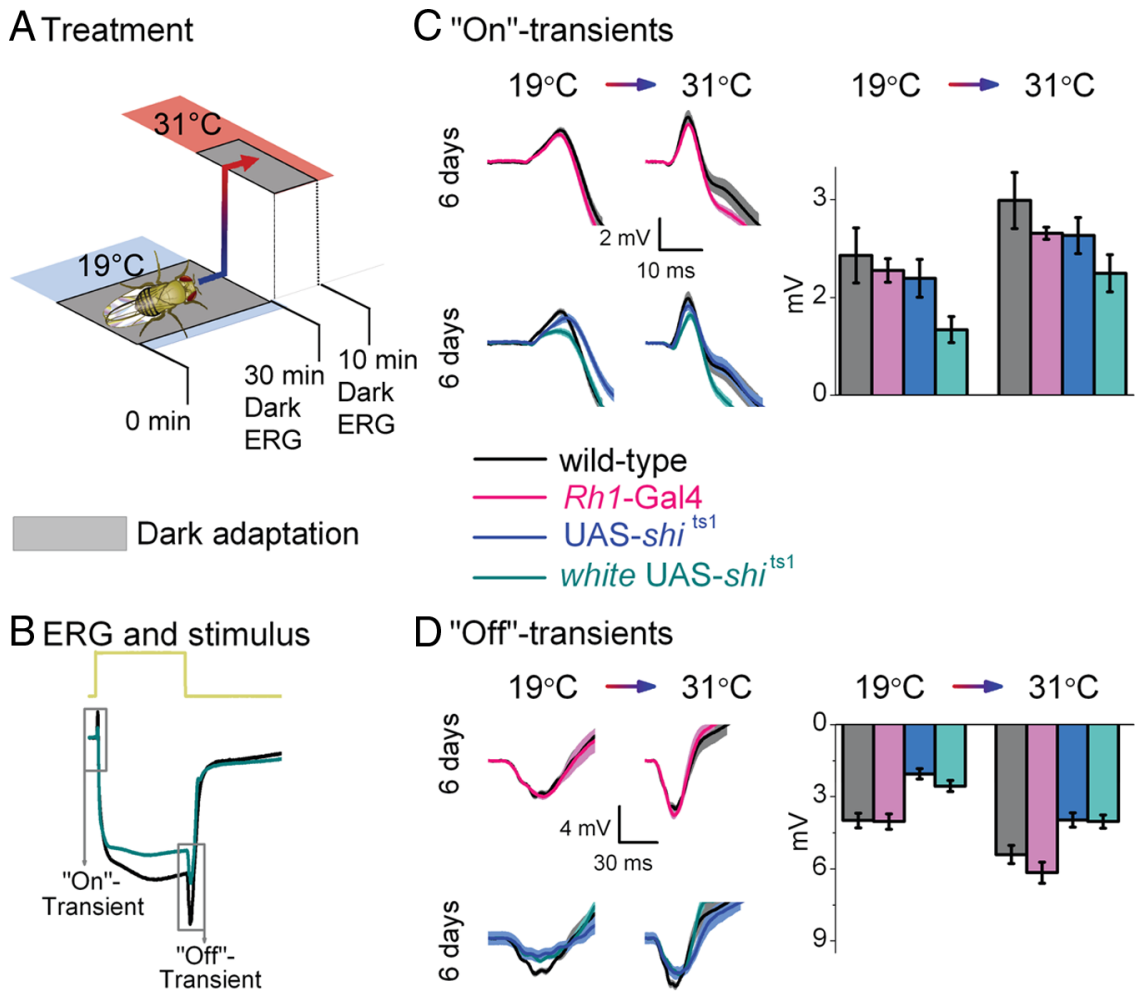

Figure 3. Neurotransmission from transgenic controls. $A$, Dark adaptation $(30 \mathrm{~min})$ at $19^{\circ} \mathrm{C}$ before dark adaptation $(10 \mathrm{~min})$ at $31^{\circ} \mathrm{C}$. B , ERGs were recorded ( $700 \mathrm{~ms}$ stimulus) after each adaptation. Traces are from dark-adapted flies at $19^{\circ} \mathrm{C}$ and $6 \mathrm{~d}$ posteclosion. The amplitude of " $0 \mathrm{n}$ "-transients $(\boldsymbol{C})$ and "Off"-transients $(\boldsymbol{D})$ quantified for wild-type (black) and homozygous transgenic controls, Rh1-Gal4 (pink), UAS-shi ${ }^{\text {ts1 }}$ (dark blue), and white UAS-shit ${ }^{\text {ts1 }}$ (blue-green). Mean \pm SEM is shown in traces and histograms with $n=6$ for each group. Age refers to days posteclosion.
Despite these conditions, "On"-transients were similar, if not identical, to wild-type transients (Fig. 3C). Therefore, none of the insertions acting on their own impaired synaptic transmission. The only deviation was from white UAS-shits $6 \mathrm{~d}$ posteclosion, which after dark adaptation at $19^{\circ} \mathrm{C}$ had "On"-transients reduced by $\sim 50 \%$ ( $0.93 \pm 0.21$ vs $2.04 \pm 0.20$ of wild type; mean $\pm \mathrm{SEM} ; p=0.003$, Bonferroni test; $n=6)$. At $31^{\circ} \mathrm{C}$, white UAS-shi ${ }^{\text {tsl }}$ photoreceptor responses approached the performance of wild type. These findings highlight that white has a deleterious effect on photoreceptor synaptic output (cf. Fig. $1 C$ ), an effect likely attributable to the reduced histamine in white mutants (Borycz et al., 2008). The "On"-transient delay in UAS-shi $i^{\text {tsl }}$ flies (Fig. 3C), suggests a small leakage effect from the UAS-shi ${ }^{\text {tsl }^{1}}$ insertion.

Assessment of Gal4 and UAS insertions To reduce the effects of the partial activation of UAS-shitsl at low temperatures while blocking neurotransmission at high temperatures, we varied the number of Rh1-Gal4 and UAS-shits insertions (Fig. 4). Altering the number of insertions or the temperature at which the flies were raised, did not yield a workable compromise to block transmission at $>31^{\circ} \mathrm{C}$ while keeping photoreceptors unaffected at $19^{\circ} \mathrm{C}$.
Prolonged light adaptation boosts the lamina ERG transients of $3 d$ posteclosion photoreceptors

In contrast to the synaptic inactivity of their dark-adapted counterparts (cf. Fig. 1C,D; Dark), after prolonged light adaptation at $19^{\circ} \mathrm{C}$, the "On"-transient of $3 \mathrm{~d}$ posteclosion white Rh1-shits photoreceptors appeared slightly delayed and larger in amplitude than those of the wild type (Fig. $2 \mathrm{C} ; 19^{\circ} \mathrm{C}$ ). Nevertheless, even without dark adaptation, white $R h 1-s h i^{\text {tsl }}$ neurotransmission deteriorated with age. At $6 \mathrm{~d}$ posteclosion, the lamina transients were severely reduced and delayed (Fig. $2 C, D$ ), resembling the recovering "On"- and "Off"-transients of $3 \mathrm{~d}$ posteclosion darkadapted flies (cf. Fig. 1C,D; Dark).

Restrictive temperatures extinguish synaptic transmission in light-adapted photoreceptors

As shown previously, warming flies to $31^{\circ} \mathrm{C}$ appeared to block synaptic transmission from white $R h 1-s h i^{\text {ts } 1}$ photoreceptors (Fig. $\left.2 C, D ; 31^{\circ} \mathrm{C}\right)$. These findings confirm that UAS-sh $i^{\text {tsl }}$ silences $E R G$ transients at restrictive temperatures (Kitamoto, 2001).

\section{Neurotransmission from transgenic controls}

The neurotransmission reduction seen in transgenic photoreceptors may stem from the independent actions of either the Gal4 or UAS insertions. Thus, as controls, we next tested flies homozygous for a single insertion. We conditioned the wild-type and transgenic flies using increased age, darkness and warming, as each of these factors on their own was sufficient to alter severely the synaptic output of $R h 1-s h i^{\text {ts } 1}$ photoreceptors. Transgenic $6 \mathrm{~d}$ posteclosion control flies were dark-adapted for $30 \mathrm{~min}$ at $19^{\circ} \mathrm{C}$, ERG tested and rapidly warmed to $31^{\circ} \mathrm{C}$, dark-adapted for another $10 \mathrm{~min}$, and retested (Fig. 3A).

\section{$R h 1-s h i^{\text {ts1 }}$ photoreceptors show decelerated voltage responses to light}

The ERG's slow component echos mostly mass-activity of photoreceptors (Heisenberg, 1971), attenuated by resistance barriers in the tissue (Pantazis et al., 2008). Thus, observing the slow component allowed us to assess the general health of phototransduction (Wang and Montell, 2007; Hardie and Postma, 2008; Pantazis et al., 2008) under each stimulus condition, tested in the previous light adaptation experiment (cf. Fig. $1 A$ ).

Dark adaptation extends the time course of the Rh1-shi ${ }^{\text {tsl }}$ ERG slow component

To clarify whether UAS-shits ${ }^{\text {ts }}$ overexpression had affected the time course of the photoreceptor response, the ERGs recorded at $19^{\circ} \mathrm{C}$ (cf. Fig. 1) were normalized. After dark adaptation, we found a slower return to baseline, in both $R h 1-s h i^{\text {tsl }}$ and white $R h 1-s h i^{\text {ts } 1}$ flies (Fig. 5A) but after light adaptation the return to baseline appeared similar to wild type (Fig. $5 B$ ). The slow return to baseline has been previously reported for homozygous $s h{ }^{\text {ts1 }}$ mutants, which had been shifted to high temperatures (Kelly and Suzuki, 1974). The amplitude of the slow component in an ERG appeared to be smaller in $R h 1-s h i^{\text {ts } 1}$ flies after dark adaptation at $19^{\circ} \mathrm{C}$ (supplemental Fig. S3, available at www.jneurosci.org as supplemental material) but the exact photoreceptor contribution to the ERG is unknown. Consequently, to examine how well changes in the slow ERG component could be attributed to changes in phototransduction, we used intracellular recordings. 


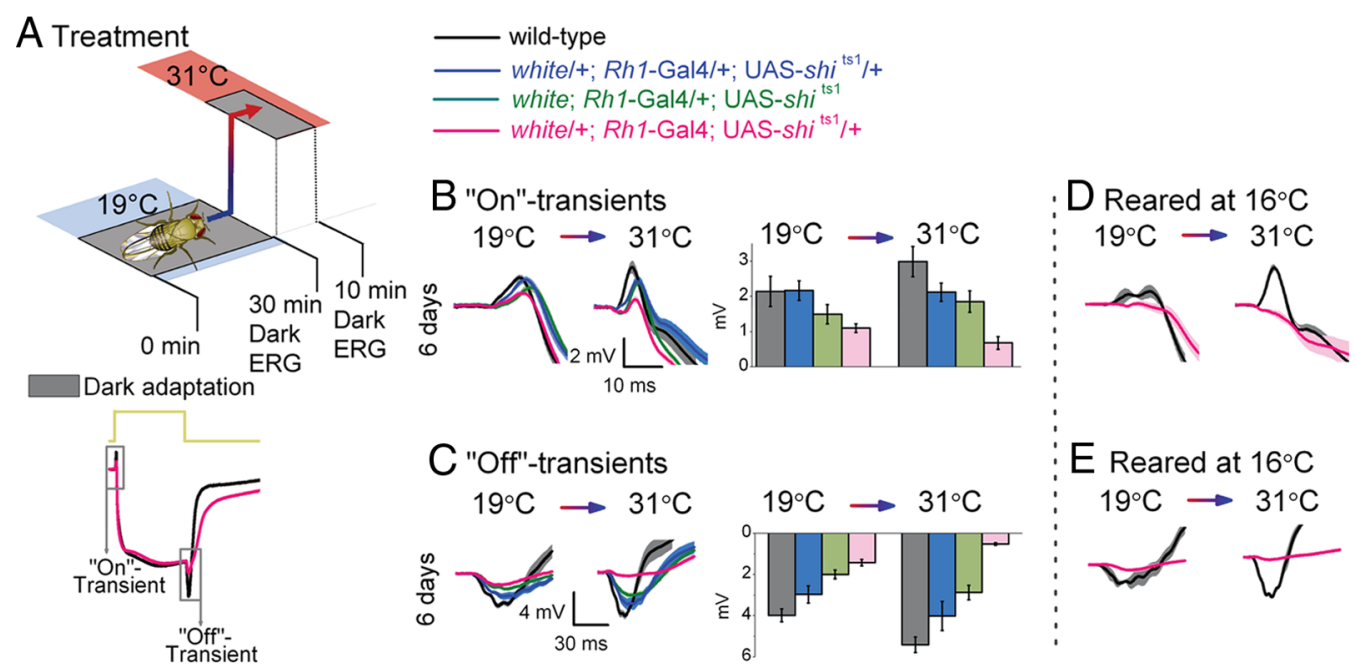

Figure 4. Assessment of Gal 4 and UAS insertions. $A$, Dark adaptation $(30 \mathrm{~min})$ at $19^{\circ} \mathrm{C}$ before dark adaptation $(10 \mathrm{~min})$ at $31^{\circ} \mathrm{C}$. ERGs were recorded $(700 \mathrm{~ms}$ stimulus) after each adaptation. Traces are from dark-adapted flies at $19^{\circ} \mathrm{C}$ and $6 \mathrm{~d}$ posteclosion. Genotypes range in number of $R h 1$-Gal4 and UAS-shits insertions. B, $\boldsymbol{C}$, The amplitude of "On"-transients $(\boldsymbol{B})$ and "Off"-transients $(\boldsymbol{C})$

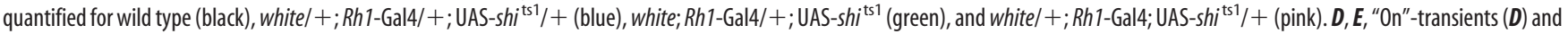
"Off"-transients $(\boldsymbol{E})$ from white/ + ; Rh 1-Gal4; UAS-shi ${ }^{\text {ts } 1} /+$ and wild-type flies raised at $16^{\circ} \mathrm{C}$ up to $3 \mathrm{~d}$ posteclosion and thereafter shifted to $18^{\circ} \mathrm{C}$. Mean \pm SEM is shown in traces and histograms with $n=6$ for each group. Age refers to days posteclosion.

Rh1-shits ${ }^{\text {ts }}$ flies exhibit slow photoreceptor voltage responses shown by intracellular recordings

We performed single-cell intracellular recordings from dark-adapted $3 \mathrm{~d}$ posteclosion $R h 1-s h i^{\text {ts } 1}$ and wild-type flies at $19^{\circ} \mathrm{C}$ by opening a small "window" in the cornea (supplemental Fig. S4, available at www.jneurosci.org as supplemental material). Voltage responses to short light pulses (10 ms) from $R h 1-s h i^{\text {ts } 1}$ photoreceptors were slower and smaller than wild type (Fig. 5C). These differences could have arisen from a slowed phototransduction sequence, from reduced feedforward and feed-back synaptic communication between photoreceptors and visual interneurons (Zheng et al., 2006; Zheng et al., 2009), or from both.

To test the impact of UAS-shits ${ }^{\text {ts }}$ on phototransduction we compared the intracellular responses of $R h 1-s h i^{\text {ts1 }}$ photoreceptors with those of blind $h d c^{\mathrm{JK} 910}$ ( $h d c$ ) mutants. Mutant $h d c$ flies cannot produce histamine (Burg et al., 1993). These flies generate an ERG response purely through phototransduction, with responses that changed voltage at a rate similar to that of wild-type photoreceptors (Fig. 5C). The delayed and much slower waveforms of $R h 1-s h i^{\text {tsl }}$ photoreceptors could not arise from synaptic silence, but instead must have resulted from slowed phototransduction. Thus, UAS-shi ${ }^{\text {ts1 }}$ overexpression not only compromises the synaptic output from photoreceptors (cf. Fig. 1), but it also decelerates the phototransduction (Fig. 5C).

Slow photoreceptors evoke slow LMC responses (van Hateren, 1992; Juusola et al., 1995), so decelerated phototransduction must be partly responsible for the sluggish synaptic

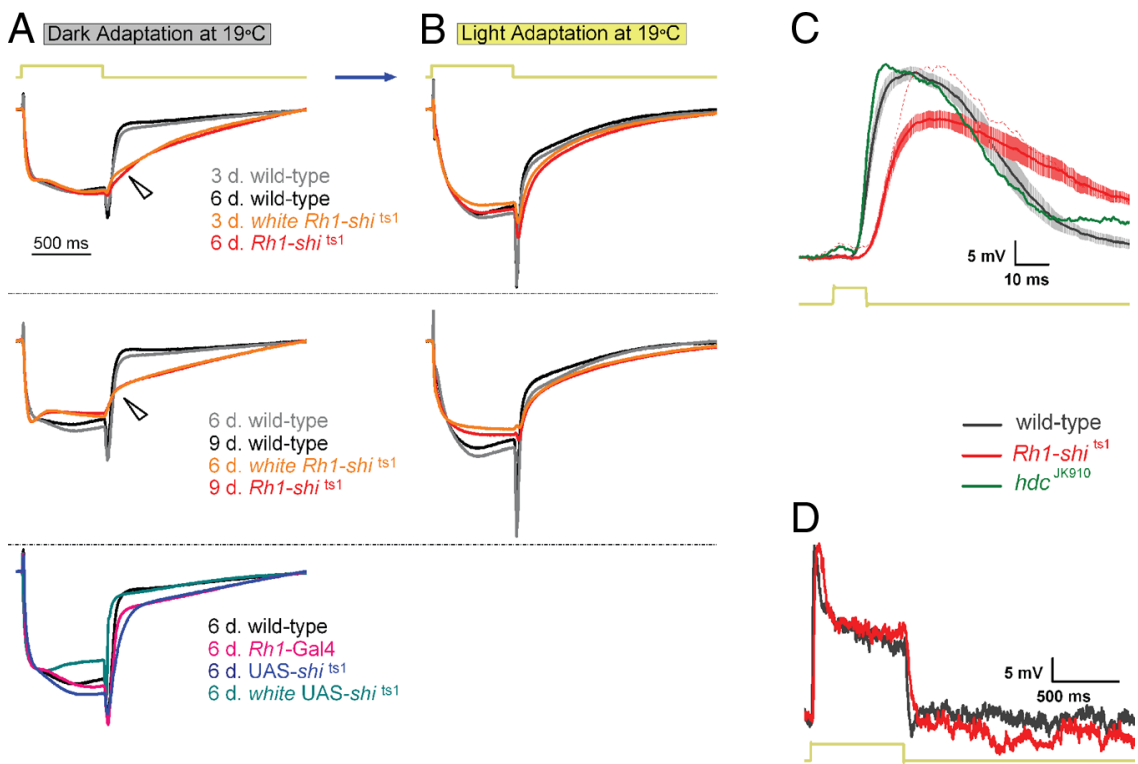

Figure 5. Rh1-shit ${ }^{\text {ts1 }}$ photoreceptors show decelerated voltage responses to light. Mean normalized ERGs $(n=6)$ to $700 \mathrm{~ms}$ stimulus, taken from Figures 1 and 3 after dark adaptation $(\boldsymbol{A})$ and after light adaptation $(\boldsymbol{B})$. Wild type is plotted for young (gray) and older (black) flies. white Rh 1 -shi ${ }^{\text {ts } 1}$ (orange) and Rh1-shi ${ }^{\text {ts } 1}$ (red) at 3 and $6 \mathrm{~d}$ posteclosion, respectively, have been plotted together. Similarly, 6 and $9 \mathrm{~d}$ posteclosion are shown together. Wild-type (black) and homozygous transgenic controls; Rh1-Gal4 (pink), UAS-shit ${ }^{\text {ts }}$ (dark blue) and white UAS-shi ${ }^{\text {ts1 }}$ (blue-green) have been plotted together (bottom). Arrows indicate differences in response waveforms between overexpressed UAS-shit ${ }^{\text {ts } 1}$ and wild type. Age refers to days posteclosion. $C$, Intracellular recordings of $3 \mathrm{~d}$ posteclosion wild-type (black) and Rh1-shit ${ }^{\text {ts } 1}$ (red) photoreceptors. Mean \pm SEM shown in traces $(n=9)$. When $R h 1$-shi ${ }^{\text {ts1 }}$ displayed the same light response amplitude (red dotted line) as wild type, the dynamics were as slow as the rest of the cells. The histamine mutant $h d \mathrm{c}^{\mathrm{J}}{ }^{1910}$ (green) does not show such delay in its response. $\boldsymbol{D}$, Representative intracellular recordings of

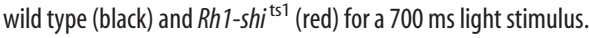

output of $R h 1-s h i^{\text {ts1 }}$ photoreceptors. To clarify this effect, we recorded intracellular responses of $R h 1-s h i^{\text {tsl }}$ and wild-type photoreceptors to a $700 \mathrm{~ms}$ light pulse and compared these waveforms to our ERG results. The delay in the response termination, observed intracellularly (Fig. 5D), was small when compared with the decaying ERGs (Fig. 5A). Hence, the latter could not reflect a slowing of the individual photoreceptor responses. 


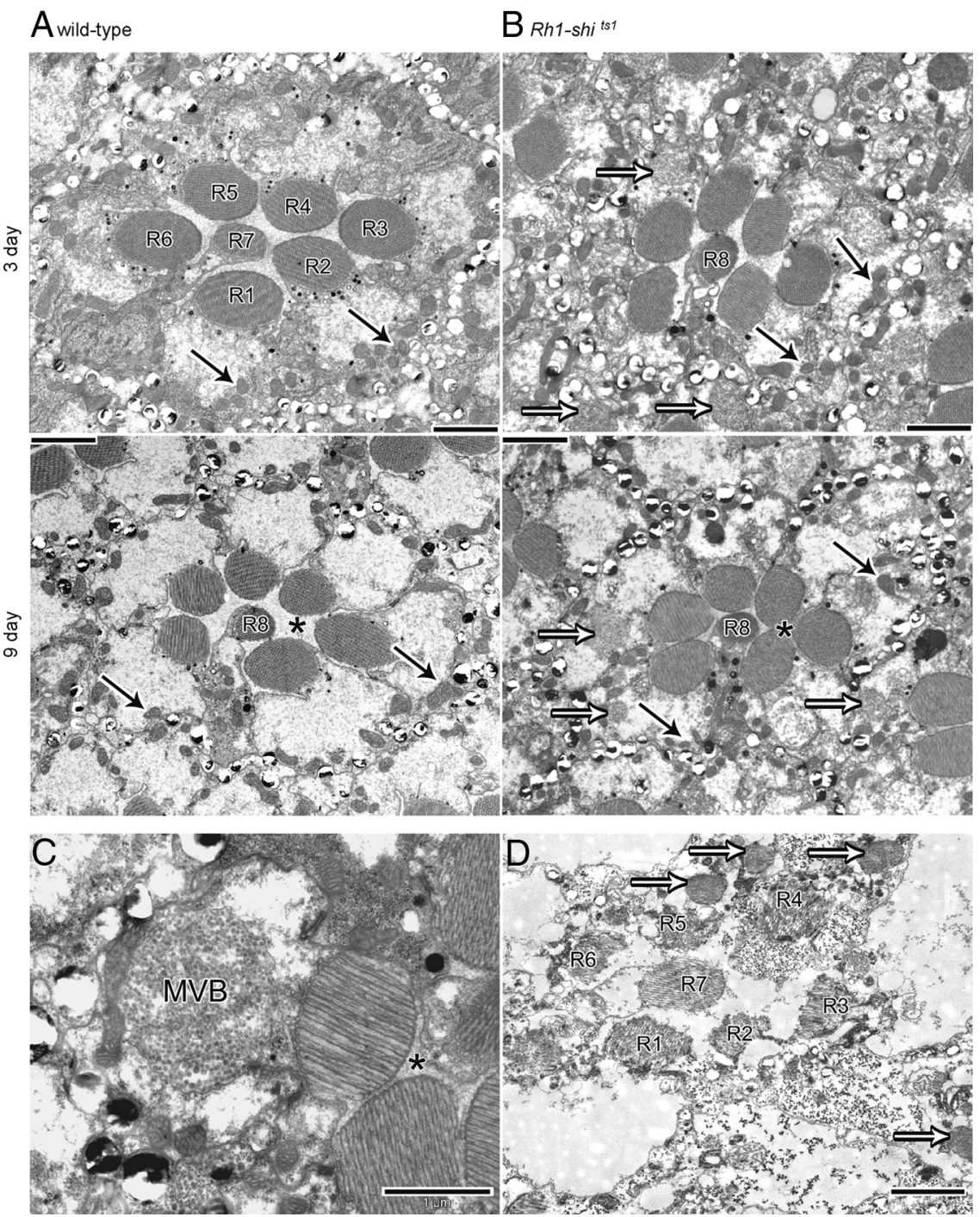

Figure 6. Overexpression of UAS-shit $i^{\text {ts } 1}$ changes retinal morphology at $19^{\circ} \mathrm{C}$. EM cross-sections of 3 and $9 \mathrm{~d}$ posteclosion wildtype $(\boldsymbol{A})$ and $R h 1$-shi ${ }^{\text {ts } 1}(\boldsymbol{B})$ retinas. Scale $=2 \mu \mathrm{m}$. C, MVBs present in Rh1-shis ${ }^{\text {ts1 }}$ photoreceptor. Scale $=1 \mu \mathrm{m} . \boldsymbol{D}, R_{h} 1$-shi ${ }^{\text {ts } 1}$ retina, raised at $25^{\circ} \mathrm{C}$, with photoreceptor $\mathrm{R} 7$ in a healthy state, demonstrating that $R h 1$-Gal 4 overexpresses UAS-shit ${ }^{\mathrm{ts}}$ only in photoreceptors R1-R6. Scale $=2 \mu \mathrm{m}$. Mitochondria (solid arrows), Multivesicular bodies (open arrows), inter-photoreceptor space (asterisk).

This sluggish transmission, observed as the decrease of "On"transients, could arise from weak voltage and calcium changes, which fail to drive exocytosis normally (Juusola et al., 1996); enlarged vesicles that lead to slower emptying (Juusola et al., 1995); reduced vesicle availability or proximity to the release site; or direct alterations to vesicle transport processes. We addressed some of these alternatives by ultrastructural examination.

\section{Overexpression of UAS-shit ${ }^{\text {ts1 }}$ changes photoreceptor morphology at $19^{\circ} \mathrm{C}$}

To examine the ultrastructure corresponding to the conditions under which ERG recordings were made (Fig. $1 A$ ), we first exposed 3 and $9 \mathrm{~d}$ posteclosion wild type and $R h 1-s h i^{\text {ts } 1}$ to either 30 min of dark adaptation, or to 30 min of dark adaptation followed by $30 \mathrm{~min}$ of light adaptation, at $18 \pm 1^{\circ} \mathrm{C}$.

Photoreceptor cell body and rhabdomere shape are altered One striking phenotype observed in $3 \mathrm{~d}$ posteclosion $R h 1-s h i^{\text {ts } 1}$ was the presence of multivesicular bodies (MVBs) in the photoreceptor cell bodies (Fig. 6A,B). By day 9, the photoreceptors were enlarged to the extent that their rhabdomeres touched. Additionally, MVBs were found in almost every photoreceptor (Fig. 6C). Further, $R h 1-s h i^{\text {tsl }}$ flies raised at $25^{\circ} \mathrm{C}$ as a control treatment showed apoptotic R1-R6, as previously reported (Acharya et al., 2003), and contained MVBs and distorted rhabdomeres. In contrast, R7/R8 had well formed and positioned rhabdomeres (Fig. 6D), consistent with being spared from the $R h 1$-driven overexpression of $s h i^{\text {tsl }}$ that occurred exclusively in R1-R6. Given the physiological changes in synaptic transmission in $R h 1-s h i^{\text {ts } 1}$, we searched for morphological changes in their photoreceptor terminals.

\section{Lamina axons of $R 1-R 6$ contain coated microtubules and vacuolated mitochondria} Wild-type photoreceptor terminals had well defined membranes and mitochondria (Fig. 7A). Conversely, Rh1-shits1 terminals contained novel electron-dense profiles (Fig. $7 B$ ). These profiles matched those found previously after overexpressing UAS-shits ${ }^{\text {tsl }}$ with GMR-Gal4 (Sun, 1998). In agreement with Sun (1998), we confirmed that these profiles were bundles of coated microtubules, based on the following criteria. When cut in longitudinal plane, each coated microtubule formed an elongate profile (supplemental Fig. S5, available at www.jneurosci.org as supplemental material). The diameter of the coated microtubules was $38.92 \pm 0.17$ $\mathrm{nm}($ mean \pm SEM) and the profiles appeared dark, with a surrounding electrondense coat (Fig. 7C). R1-R6 terminals from flies at $9 \mathrm{~d}$ posteclosion showed bundles of cross-linked microtubules akin to those reported from in vitro experiments (Shpetner and Vallee, 1989) (Fig. 7D). In contrast, uncoated microtubules seen in LMCs (Fig. 7E), had an average diameter of $24.19 \pm 0.40 \mathrm{~nm}$ (mean \pm SEM; $n=27$ ), as seen previously (Friedman, 1971). The bundling of microtubules became extensive with age. The number of microtubules per $\mu \mathrm{m}^{2}$ in the terminals of $R h 1-s h i^{\text {ts } 1}$ in $3 \mathrm{~d}$ posteclosion was $15.44 \pm 4.07$ and in $9 \mathrm{~d}$ posteclosion was $155.04 \pm 41.33$ ( $n=28$ or 26 terminals, respectively). Coated microtubules were not observed in wild-type terminals. In many cases the coated microtubules occupied the entire profile of $9 \mathrm{~d}$ posteclosion photoreceptor terminals (cf. Fig. $7 B$; supplemental Fig. S5, available at www.jneurosci.org as supplemental material). In addition, mitochondrial profiles in $9 \mathrm{~d}$ posteclosion terminals were enlarged and vacuolated, and appeared typical of apoptotic neurons (cf. Fig. $7 B$ ).

In contrast to mitochondria in the terminals of $R h 1-s h i^{\text {ts } 1}$ photoreceptors at $9 \mathrm{~d}$ posteclosion, the cell bodies had healthy mitochondria (Fig. $6 \mathrm{~B}$ ). We take this observation to indicate that widespread microtubule bundling in the axon interferes with the normal function of a neuron, preventing the proper transport of 
organelles to the synaptic terminal and consequently perhaps also affecting synaptic transmission. It appears that to keep axonal transport functional, $R h 1-s h t^{\text {ts } 1}$ photoreceptors progressively accrete additional microtubules, because these clearly outnumber those seen in control terminals (Fig. $7 A, B$ ).

Rh1-shi ${ }^{\text {tsl }}$ photoreceptor terminals contain fewer vesicles than wild type In $R h 1-s h i^{\text {ts } 1}$ terminals $3 \mathrm{~d}$ posteclosion, there were significantly fewer vesicle profiles than in wild type, but their numbers did not differ between dark- and light adaptation (Fig. $7 F$ ). The dense packing of microtubule bundles in most $R h 1$-shi $i^{\text {ts } 1}$ terminals at $9 \mathrm{~d}$ posteclosion left little space for synaptic vesicles, which consequently were not counted.

Immunogold labeling confirms that the microtubule coat is dynamin

Given that dynamin behaves as a microtubule-associated protein (MAP) in vitro (Shpetner and Vallee, 1989), we investigated whether the electron-dense microtubule coating was overexpressed dynamin (Fig. $8 A-G$ ). We directed an antibody against dynamin, using a postembedding immunogold method. Gold particles were distributed near the membranes and capitate projections of wild type and $R h 1-s h{ }^{\text {tsl }}$ terminals (Fig. $8 A-D$ ). In addition, gold particles tagged the cytoplasmic space close to coated microtubules in many $R h 1-s h i^{\text {ts } 1}$ terminals (Fig. $8 C-G)$, in a pattern not observed in wild type. Adjacent LMC profiles, which acted as an internal control, lacked such cytoplasmic labeling, confirming the specificity of gold labeling to sites with dynamin overexpression (Fig. 8E). At high magnification, gold particles were observed adjacent to coated microtubules and near the filaments that extended from microtubules (Fig. $8 G$ ).

\section{Microtubule coat is present in other neurons when UAS-shits is overexpressed \\ To test whether the interaction between overexpressed UAS-shit ${ }^{\text {ts } I}$ and microtubules is exclusive to photoreceptor cells, we targeted UAS-shits to a selection of lamina cells with the driver MJ85b- Gal4 (Joiner and Griffith, 1997). TEM sectioning revealed exten- sive microtubule bundling in $\mathrm{L} 3$ and other unidentified neurons (tentatively amacrine or T1 profiles) (Fig. $9 A, B$ ), which extend thin spines between photoreceptor cells (Fig. 9C).}

\section{Discussion}

We have shown that, at $19^{\circ} \mathrm{C}$, transgenic photoreceptors that overexpress UAS-shi $i^{\text {ts }}$ display anomalous synaptic transmission when dark-adapted or aged. Even at previously reported permissive temperatures (Kitamoto, 2001), overexpressing UAS-sh ${ }^{\text {ts }^{1}}$ in photoreceptors causes a significant deceleration in photo-

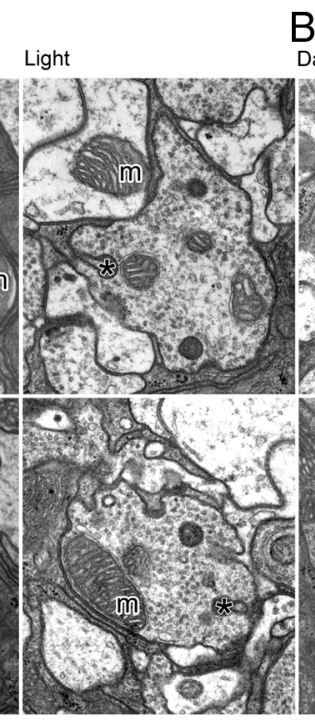

$\mathrm{B}_{\text {Rh1-shitst }}$

Dark Light
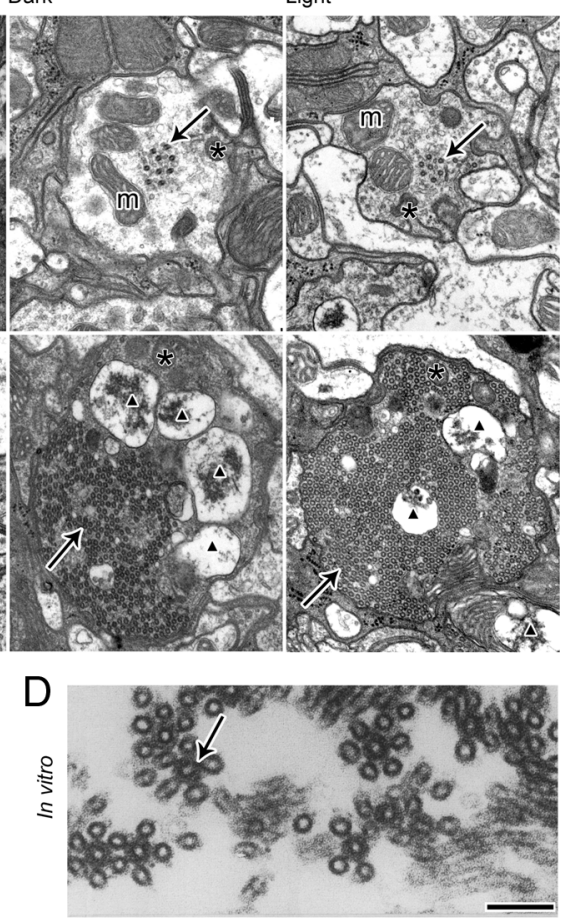

$\mathrm{F}$

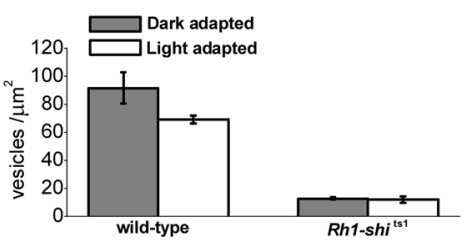

Figure 7. Overexpression of UAS-shit ${ }^{\text {ts }}$ changes photoreceptor terminal morphology at $19^{\circ} \mathrm{C} . A, B$, EM cross-sections of 3 and $9 \mathrm{~d}$ posteclosion wild-type $(\boldsymbol{A})$ and $R h \mathrm{~h}^{-} \mathrm{sh}^{\mathrm{ts} 1}(\boldsymbol{B})$ terminals, reared at $18^{\circ} \mathrm{C}$. Flies were exposed to $30 \mathrm{~min}$ of darkness (Dark) or to 30 a of vesicles per square micrometer for $3 \mathrm{~d}$ posteclosion wild type (dark-adapted; $91.40 \pm 11.02$, light-adapted; $68.86 \pm 3.07$ ) and Rh1-shi ${ }^{\text {ts } 1}$ (dark-adapted; $12.70 \pm 0.78$, light-adapted; $11.70 \pm 2.26$ ) terminals. Mean \pm SEM is given.

transduction, a significant reduction of neurotransmitter release and severe alterations in cell shape when compared with wild type. At $19^{\circ} \mathrm{C}$, the induced morphological changes in $R h 1-s h i^{\text {ts } 1}$ photoreceptors included: widespread vacuolation of mitochondrial profiles, significantly reduced numbers of vesicles, and photoreceptors filled with dynamin-coated microtubules. The physiological and morphological changes shown here seem to extend to changes in behavior, insofar as Keller (2002) reported a significant drop in visual performance in flies overexpressing UAS-shit $i^{\text {ts } 1}$ at $19^{\circ} \mathrm{C}$ in photoreceptors R1-R8 (GMR-Gal4).

When we replicated the conditions used by Kitamoto (2001) and recorded ERGs from light-adapted flies at $3 \mathrm{~d}$ posteclosion, we also obtained transientless ERGs at $31^{\circ} \mathrm{C}$. However, at $19^{\circ} \mathrm{C}$ dark adaptation and age made significant changes to phototransduction and neurotransmission not found by Kitamoto (2001). We also showed that the onset of these phenotypic changes is accelerated in flies containing the white-null mutation $\left(w^{1118}\right)$. Thus caution is needed when using white mutant background flies (Borycz et al., 2008). In an attempt to yield a complete blockade of endocytosis at the restrictive temperature while retaining wild-type responses at lower temperatures, we decreased the 

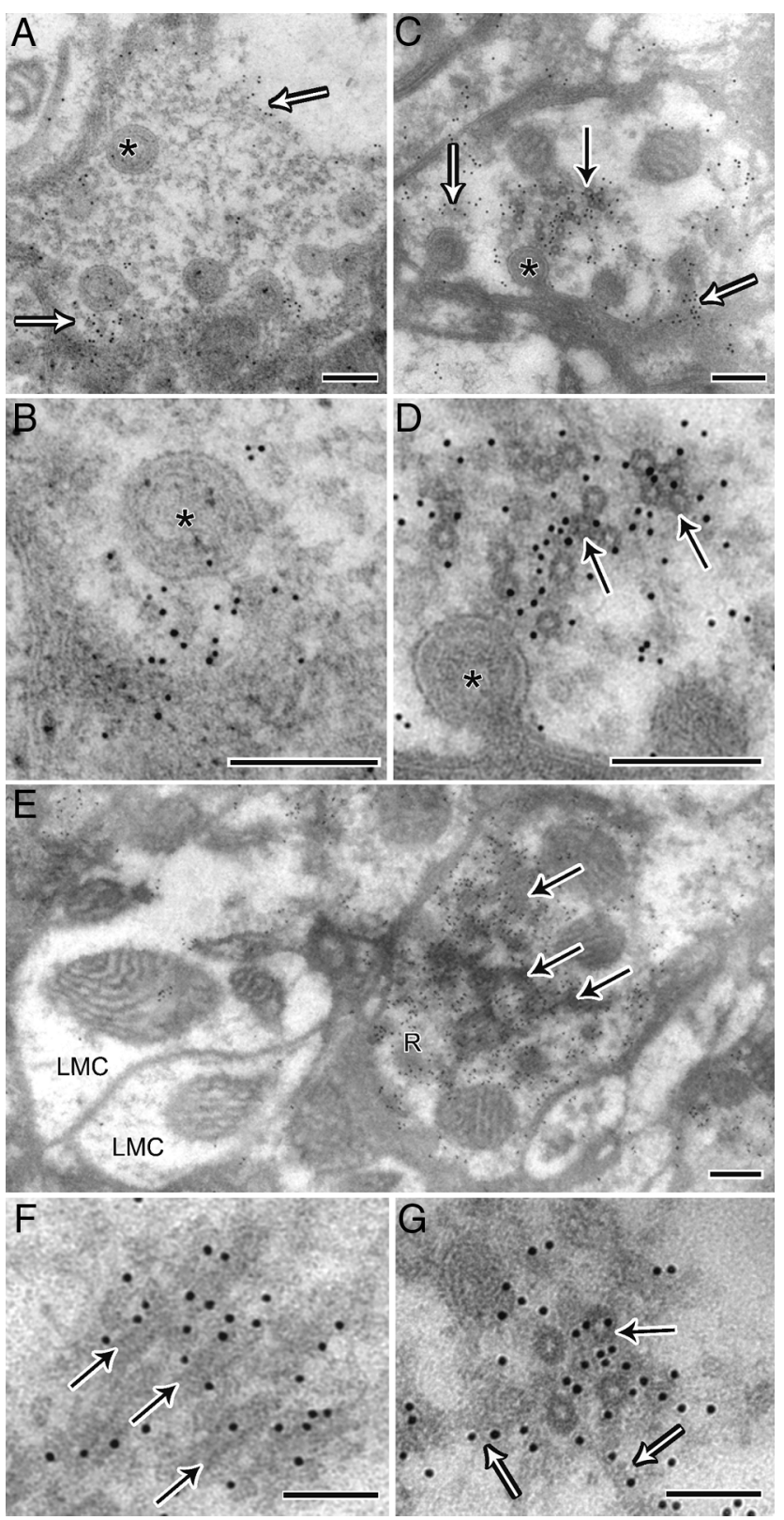

Figure 8. Immunogold labeling confirms that the microtubule coat is dynamin. A, Wild-type terminal showing $10 \mathrm{~nm}$ gold immunolabeling in proximity to the membrane, indicated by open arrows and capitate projections (asterisk). $\boldsymbol{B}$, High magnification of $\boldsymbol{A}$. C, Photoreceptor terminal from $R h 1$-shi ${ }^{\text {ts } 1}$, which in addition to labeling near capitate projections (open arrows), has labeling in the cytoplasm near coated microtubules (solid arrow). D, High magnification of C. E, Terminal from Rh1-shis ${ }^{\text {ts1 }}$ showing labeling of oblique coated microtubules in the cytoplasm. Note that adjacent LMC profiles do not have cytoplasmic labeling, thus confirming the specificity of gold labeling to overexpressed shits dynamin. Scale $(\boldsymbol{A}-\boldsymbol{E}), 200 \mathrm{~nm}$. $\boldsymbol{F}, \boldsymbol{G}$, High magnification of labeled oblique $(\boldsymbol{F})$ and cross-section of coated $(\boldsymbol{G})$ microtubules (solid arrow) showing that labeling extends to filaments adjacent (open arrow). Scale $(\boldsymbol{F}-\boldsymbol{G}), 100 \mathrm{~nm}$.

number of transgenic insertions. We failed to achieve such a phenotype, possibly because dynamin has an intrinsic thermo-liable nature (Grant et al., 1998) rather than a discrete switch mechanism.

\section{Mutant dynamin overexpression decelerates phototransduction at $19^{\circ} \mathrm{C}$}

Intracellular recordings from photoreceptors showed that phototransduction was slowed by UAS-shis ${ }^{\text {ts }}$ overexpression
A

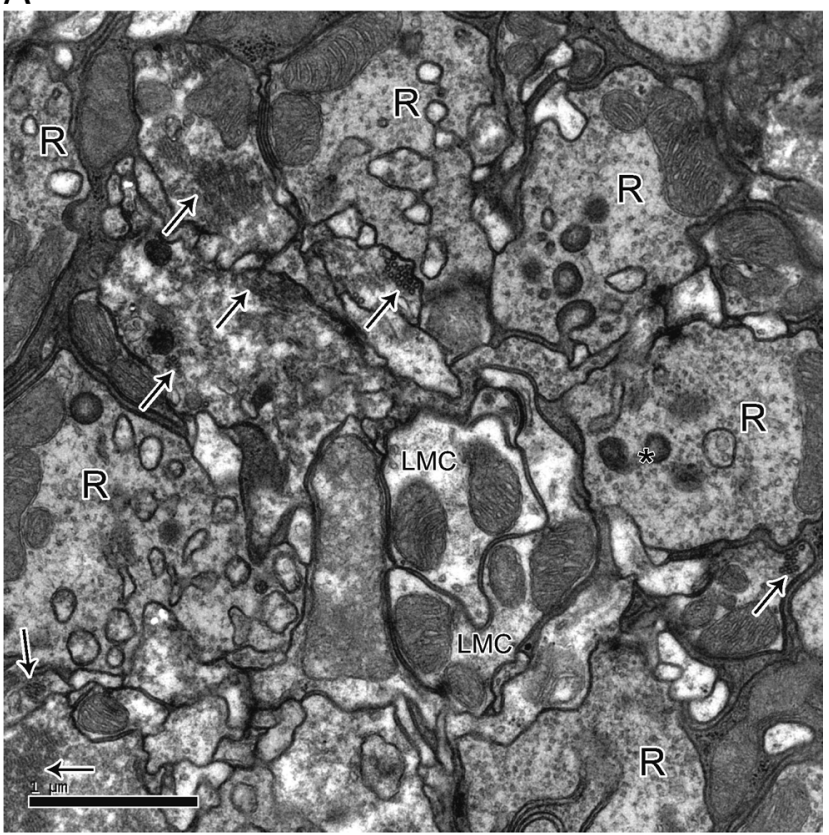

B

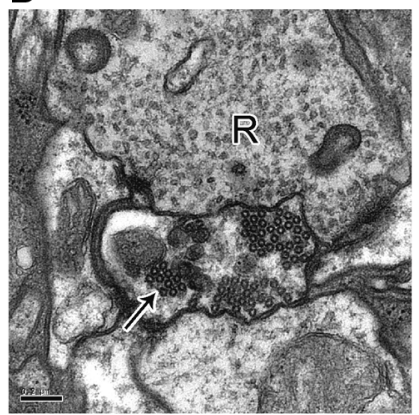

C

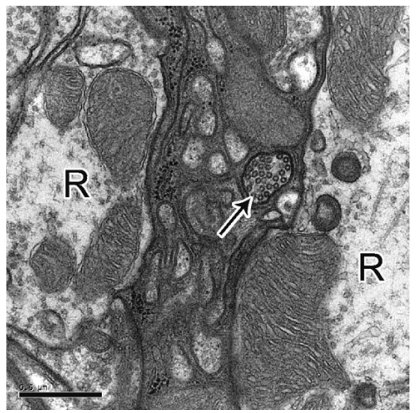

Figure 9. Microtubule coat is present in other neurons when UAS-shits ${ }^{\text {st }}$ is overexpressed. A, MJ85b-shi ${ }^{\text {ts } 1}$ lamina cartridge showing coated microtubules (arrows) in lamina cells and not in photoreceptor terminals (R). Scale, $1 \mu \mathrm{m}$. $\boldsymbol{B}$, Close-up of coated microtubules in a lamina cell. Scale, $0.2 \mu \mathrm{m}$. C, Lamina cell spine packed with coated microtubules. Scale, $0.5 \mu \mathrm{m}$.

after dark adaptation. This finding suggests that UAS-shit $i^{\text {tsl }}$ overexpression might compete with or hinder endocytotic or translocation-dependent reactions in phototransduction, such as Rh1, trpl, Arr1 or Arr2 cycles for the normal initiation and termination of light-evoked responses (Satoh and Ready, 2005; Frechter and Minke, 2006; Hardie and Postma, 2008). Decelerated phototransduction would in turn slow down the rate of transmitter release (van Hateren, 1992; Juusola et al., 1995). After dark adaptation, the return to base line of the $R h 1-s h i^{{ }^{\text {ts } 1}}$ ERG was slowed at $19^{\circ} \mathrm{C}$, as also documented in $s h i^{\text {tsl }}$ mutants shifted to $28^{\circ} \mathrm{C}$ (Kelly and Suzuki, 1974). The reasons for such a delay are elusive. Possibly the altered neurotransmission resulting in small and delayed "Off"-transients integrates with the slow component of the waveform, changing the shape of the ERG. Alternatively, overexpressing UAS-shi $i^{\text {tsl }}$ could in some way alter the metabolic homeostasis in the retina. Increased extracellular $\mathrm{K}^{+}$concentration depolarizes slow responding pigment cells in the bee retina (Coles and Orkand, 1983), for example, so that increased $\mathrm{K}^{+}$ concentrations may contribute in the ERG to a delayed return to baseline. 


\section{Mutant dynamin overexpression changes photoreceptor shape}

UAS-shi $i^{\text {tsl }}$ overexpression at $19^{\circ} \mathrm{C}$ induced enlarged photoreceptor cell bodies, noticeable by their reduced inter-rhabdomeric space, which resemble changes previously reported in HtTA cells induced to express the active dynamin mutant form ele 1 for $24 \mathrm{~h}$ (Damke et al., 1994). Furthermore, large numbers of multivesicular bodies were observed, a phenotype reported for a mutant with defective endocytotic machinery and neurotransmitter recycling (Dermaut et al., 2005). For many published behavioral assays, flies overexpressing UAS-shits ${ }^{\text {ts }}$ are commonly reared at a reported permissive temperature of $25^{\circ} \mathrm{C}$. However, when UAS-shis $i^{\text {tsl }}$ is overexpressed in photoreceptors, and flies are reared at $23^{\circ} \mathrm{C}$ (Acharya et al., 2003) or at $25^{\circ} \mathrm{C}$ (as in this study), the effects of dynamin overexpression are cell lethal, and result in apoptosis.

\section{Dynamin coats and cross-links microtubules}

The action of shibire ${ }^{\text {tsl }}$ in photoreceptors has been widely interpreted in terms of its effects on endocytosis (Fabian-Fine et al., 2003). Although shibire's role in endocytosis (Kosaka and Ikeda, 1983) has overshadowed dynamin's other actions in Drosophila, dynamin was in fact initially discovered as a MAP (Vallee, 1992). Thus, the interaction between dynamin and microtubules has long been known to occur in vitro (Shpetner and Vallee, 1989), but to our knowledge dynamin has not previously been shown to coat and cross-link microtubules in living cells. The microtubules we find decorated with dynamin are a hallmark of UAS-shits overexpression in the terminals of $R h 1-s h i^{\text {ts } 1}$ photoreceptors. We also confirmed that shibire can induce microtubule bundling in other lamina neurons.

Cross-linked microtubules, which aggregate into bundles, are a distinctive feature of many neurons; for example in the "tubular body", a dendritic specialization necessary for transduction in the wild-type campaniform mechanoreceptors of Drosophila (Toh, 1985). Initial axonal segments of multipolar neurons (Palay et al., 1968; Westrum and Gray, 1976) are likewise recognized by the presence of cross-linked microtubules. The protein causing this structural phenotype in mammalian neurons has not been reported.

Our results demonstrate that shibire can indeed act as a MAP, and induce microtubule bundling in vivo. Although the bundling of microtubules seen in the axon and terminals of $R h 1-s h i^{\text {ts } 1}$ photoreceptors incorporates a dynamin coat, and thus appears to result from shibire ${ }^{\text {tsl }}$ overexpression, the exact wild-type location of the dynamin-microtubule interaction is unknown. It is possible that only cells that require most cytoskeletal support, or place particular demands on axoplasmic transport, translocate MAPs in sufficient concentration to bundle their microtubules in specific locations. Even when dynamin is expressed at high concentrations, the presence of GTP may prevent dynamin self assembly around microtubules, as shown in membrane-bead preparations (Pucadyil and Schmid, 2008). It is feasible that the reduced GTPase activity induced by a single nucleotide change in the GTPbinding domain of $s h i^{\text {tsl }}$ (Grant et al., 1998), mimics low GTP availability. If this were the case, the self assembly of dynamin and cross-linking of microtubules observed in $R h 1-s h i^{\text {tsl }}$ terminals is in accordance with the suggestion that without GTP, self assembled dynamin is in a "kinetically trapped state" (Pucadyil and Schmid, 2008). Furthermore, the shibire gene has seven splice variants (Chen et al., 1991) the intracellular location of which may not be uniform. Splice variation could be important, because another MAP protein, tau (MAPt), causes microtubule bundling in vitro, but only when specific splice variants are used and only at high concentrations (Scott et al., 1992).

Dynamin-microtubule interactions may be involved in functions other than microtubule bundling or endocytosis, such as sorting of vesicular cargo. In mammals, dynamin 2 associates with the Golgi apparatus (Maier et al., 1996). More recently, dynamin 2 has been shown to be necessary for maintaining dynamic instability of microtubules and to form mature Golgi complexes (Tanabe and Takei, 2009). Given that Drosophila has a single dynamin isoform, one of the shibire splice variants could take on a similar role to that of dynamin 2 . It is conceivable that the microtubule interaction here described for shibire ${ }^{\text {tsl }}$ may be crucial for dynamin-like proteins (DLPs). DLPs, which possess a GTPase domain and can self assemble but lack the pleckstrin homology domain and the proline rich domain, are involved in a multitude of processes related to membrane shape (Hinshaw, 2000; Praefcke and McMahon, 2004). For example, DLP1 is necessary for mitochondrial fission (Yu et al., 2005) and has also been shown to localize to vesicles that coalign with microtubules and the endoplasmic reticulum (Yoon et al., 1998).

Although the endocytotic function of the shibire ${ }^{\text {ts1 }}$ homozygous mutant is altered at $19^{\circ} \mathrm{C}$, as shown by the reduced number of vesicles in its R1-R6 terminals (MacIntosh, 1996), it must be emphasized that bundled microtubules have not been found in the photoreceptor terminals of the shibire ${ }^{\text {tsl }}$ mutant (MacIntosh, 1996). Additionally, Zheng et al. (2006) performed intracellular recordings of shibire ${ }^{\text {ts } 1}$ mutant photoreceptors and reported wild-type-like responses at $19^{\circ} \mathrm{C}$ and reversible silencing of neurotransmission at $29^{\circ} \mathrm{C}$. We therefore suggest that it is the high levels of dynamin overexpression, in common with its mutant structure, which together overcome the normal function of wildtype dynamin, and caution against uncritical use of the UAS$s h i^{\text {ts1 }}$ transgene to interrupt synaptic function reversibly. In graded neurons with high levels of neurotransmitter release (Juusola et al., 1995; Uusitalo et al., 1995b; Juusola et al., 1996), high levels of shibire ${ }^{\text {ts1 }}$ overexpression may be required to block neurotransmission but may potentially cause apoptosis. In comparison, low overexpression of shibire ${ }^{\text {tsl }}$ in presynaptic spiking neurons may prevent action potential generation in postsynaptic cells without completely blocking the synapse. In either case, however, optimal synapse control may be difficult to achieve. Gal4 drivers are in fact notorious for the wide range of intensity in their expression between different lines; the remaining elements of the neural network, that lack shibire ${ }^{\text {tsl }}$ overexpression, may moreover reroute and reshape neural communication to compensate for any altered function in the Ga4-shi ${ }^{\text {ts1 }}$-expressing neuron (Vähäsöyrinki et al., 2006; Zheng et al., 2006; Nikolaev et al., 2009). Furthermore, it would be paramount to confirm, with a physiological diagnostic, that shibire ${ }^{\text {ts } 1}$ overexpression prevents adequate information flow. Finally, ceramidase overexpression prevents photoreceptor degeneration induced by $s h i^{\text {tsl }}$ (Acharya et al., 2003), providing one avenue to spare the UAS-shits ${ }^{\text {tsl }}$ generated defects in endocytosis at low temperatures.

We conclude that the use of UAS-shi ${ }^{\text {tsl }}$ in photoreceptors and lamina neurons of Drosophila at $19^{\circ} \mathrm{C}$ causes nonreversible phenotypes and confirms an additional action of dynamin in microtubule binding. Our results indicate that careful review on the toxicity and secondary effects caused by overexpressing mutant dynamin is needed. 


\section{References}

Acharya U, Patel S, Koundakjian E, Nagashima K, Han X, Acharya JK (2003) Modulating sphingolipid biosynthetic pathway rescues photoreceptor degeneration. Science 299:1740-1743.

Bähner M, Frechter S, Da Silva N, Minke B, Paulsen R, Huber A (2002) Light-regulated subcellular translocation of Drosophila TRPL channels induces long-term adaptation and modifies the light-induced current. Neuron 34:83-93.

Beramendi A, Peron S, Casanova G, Reggiani C, Cantera R (2007) Neuromuscular junction in abdominal muscles of Drosophila melanogaster during adulthood and aging. J Comp Neurol 501:498-508.

Borycz J, Borycz JA, Kubów A, Lloyd V, Meinertzhagen IA (2008) Drosophila $\mathrm{ABC}$ transporter mutants white, brown and scarlet have altered contents and distribution of biogenic amines in the brain. J Exp Biol 211:3454-3466.

Brand AH, Perrimon N (1993) Targeted gene expression as a means of altering cell fates and generating dominant phenotypes. Development 118:401-415.

Burg MG, Sarthy PV, Koliantz G, Pak WL (1993) Genetic and molecular identification of a Drosophila histidine-decarboxylase gene required in photoreceptor transmitter synthesis. EMBO J 12:911-919.

Chen DM, Stark WS (1993) Effects of temperature on visual receptors in temperature-sensitive paralytic shibire $\left(\right.$ shi $\left.^{\text {ts }}\right)$ mutants in Drosophila. J Insect Physiol 39:385-392.

Chen MS, Obar RA, Schroeder CC, Austin TW, Poodry CA, Wadsworth SC, Vallee RB (1991) Multiple forms of dynamin are encoded by shibire, a Drosophila gene involved in endocytosis. Nature 351:583-586.

Chorna-Ornan I, Tzarfaty V, Ankri-Eliahoo G, Joel-Almagor T, Meyer NE, Huber A, Payre F, Minke B (2005) Light-regulated interaction of Dmoesin with TRP and TRPL channels is required for maintenance of photoreceptors. J Cell Biol 171:143-152.

Coles JA, Orkand RK (1983) Modification of potassium movement through the retina of the drone (Apis mellifera male;) by glial uptake. J Physiol 340:157-174.

Coombe PE (1986) The large monopolar cells L1 and L2 are responsible for ERG transients in Drosophila. J Comp Physiol A Neuroethol Sens Neural Behav Physiol Neuroethol Sens Neural Behav Physiol 159:655-665.

Coombe PE, Heisenberg M (1986) The structural brain mutant Vacuolar medulla of Drosophila melanogaster with specific behavioral defects and cell degeneration in the adult. J Neurogenet 3:135-158.

Cronin MA, Diao F, Tsunoda S (2004) Light-dependent subcellular translocation of $\mathrm{G}_{\mathrm{q}} \alpha$ in Drosophila photoreceptors is facilitated by the photoreceptor-specific myosin III NINAC. J Cell Sci 117:4797-4806.

Damke H, Baba T, Warnock DE, Schmid SL (1994) Induction of mutant dynamin specifically blocks endocytic coated vesicle formation. J Cell Biol 127:915-934.

Delgado R, Maureira C, Oliva C, Kidokoro Y, Labarca P (2000) Size of vesicle pools, rates of mobilization, and recycling at neuromuscular synapses of a Drosophila mutant, shibire. Neuron 28:941-953.

Dermaut B, Norga KK, Kania A, Verstreken P, Pan H, Zhou Y, Callaerts P, Bellen HJ (2005) Aberrant lysosomal carbohydrate storage accompanies endocytic defects and neurodegeneration in Drosophila benchwarmer. J Cell Biol 170:127-139.

Duffy JB (2002) GAL4 system in Drosophila: a fly geneticist's Swiss army knife. Genesis 34:1-15.

Estes PS, Roos J, van der Bliek A, Kelly RB, Krishnan KS, Ramaswami M (1996) Traffic of dynamin within individual Drosophila synaptic boutons relative to compartment-specific markers. J Neurosci 16:5443-5456.

Fabian-Fine R, Verstreken P, Hiesinger PR, Horne JA, Kostyleva R, Zhou Y, Bellen HJ, Meinertzhagen IA (2003) Endophilin promotes a late step in endocytosis at glial invaginations in Drosophila photoreceptor terminals. J Neurosci 23:10732-10744.

Frechter S, Minke B (2006) Light-regulated translocation of signaling proteins in Drosophila photoreceptors. J Physiol Paris 99:133-139.

Frechter S, Elia N, Tzarfaty V, Selinger Z, Minke B (2007) Translocation of $\mathrm{G}_{\mathrm{q}} \alpha$ mediates long-term adaptation in Drosophila photoreceptors. J Neurosci 27:5571-5583.

Freeman M (1996) Reiterative use of the EGF receptor triggers differentiation of all cell types in the Drosophila eye. Cell 87:651-660.

Friedman MH (1971) Arm-bearing microtubules associated with an unusual desmosome-like junction. J Cell Biol 49:916-920.

Gao S, Takemura SY, Ting CY, Huang S, Lu Z, Luan H, Rister J, Thum AS,
Yang M, Hong ST, Wang JW, Odenwald WF, White BH, Meinertzhagen IA, Lee CH (2008) The neural substrate of spectral preference in Drosophila. Neuron 60:328-342.

Gengs C, Leung HT, Skingsley DR, Iovchev MI, Yin Z, Semenov EP, Burg MG, Hardie RC, Pak WL (2002) The target of Drosophila photoreceptor synaptic transmission is a histamine-gated chloride channel encoded by ort (hclA). J Biol Chem 277:42113-42120.

Goode NP, Shires M, Crellin DM, Khan TN, Mooney AF (2004) Postembedding double-labeling of antigen-retrieved ultrathin sections using a Silver enhancement-controlled sequential immunogold (SECSI) technique. J Histochem Cytochem 52:141-144.

Grant D, Unadkat S, Katzen A, Krishnan KS, Ramaswami M (1998) Probable mechanisms underlying interallelic complementation and temperaturesensitivity of mutations at the shibire locus of Drosophila melanogaster. Genetics 149:1019-1030.

Han J, Reddig K, Li HS (2007) Prolonged $\mathrm{G}_{\mathrm{q}}$ activity triggers fly rhodopsin endocytosis and degradation, and reduces photoreceptor sensitivity. EMBO J 26:4966-4973.

Hardie RC (1987) Is histamine a neurotransmitter in insect photoreceptors? J Comp Physiol A 161:201-213.

Hardie RC (1989) A histamine-activated chloride channel involved in neurotransmission at a photoreceptor synapse. Nature 339:704-706.

Hardie RC, Postma M (2008) Phototransduction in microvillar photoreceptors of Drosophila and other invertebrates. In: The senses: a comprehensive reference, Vol 1: Vision I (Albright TD, Masland R, eds), pp 77-130. San Diego: Academic.

Heisenberg M (1971) Separation of receptor and lamina potentials in the electroretinogram of normal and mutant Drosophila. J Exp Biol 55:85-100.

Hinshaw JE (2000) Dynamin and its role in membrane fission. Annu Rev Cell Dev Biol 16:483-519.

Joiner MLA, Griffith LC (1997) CaM kinase II and visual input modulate memory formation in the neuronal circuit controlling courtship conditioning. J Neurosci 17:9384-9391.

Juusola M, Hardie RC (2001) Light adaptation in Drosophila photoreceptors: I. Response dynamics and signaling efficiency at $25^{\circ} \mathrm{C}$. J Gen Physiol 117:3-25.

Juusola M, Uusitalo RO, Weckström M (1995) Transfer of graded potentials at the photoreceptor-interneuron synapse. J Gen Physiol 105:117-148.

Juusola M, French AS, Uusitalo RO, Weckström M (1996) Information processing by graded-potential transmission through tonically active synapses. Trends Neurosci 19:292-297.

Keller A (2002) Genetic intervention in sensory systems of a fly. Dr. rer. nat. thesis. Genetik und Neurobiologie. Würzburg, Germany: der Bayerischen Julius-Maximilians-Universität Würzburg.

Kelly LE, Suzuki DT (1974) The effects of increased temperature on electroretinograms of temperature-sensitive paralysis mutants of Drosophila melanogaster. Proc Natl Acad Sci U S A 71:4906-4909.

Kitamoto T (2001) Conditional modification of behavior in Drosophila by targeted expression of a temperature-sensitive shibire allele in defined neurons. J Neurobiol 47:81-92.

Kosaka T, Ikeda K (1983) Reversible blockage of membrane retrieval and endocytosis in the garland cell of the temperature-sensitive mutant of Drosophila melanogaster, shibire ${ }^{\text {ts1 }}$. J Cell Biol 97:499-507.

Kosloff M, Elia N, Joel-Almagor T, Timberg R, Zars TD, Hyde DR, Minke B, Selinger Z (2003) Regulation of light-dependent Gq $\alpha$ translocation and morphological changes in fly photoreceptors. EMBO J 22:459-468.

Kramer JM, Staveley BE (2003) GAL4 causes developmental defects and apoptosis when expressed in the developing eye of Drosophila melanogaster. Genet Mol Res 2:43-47.

Kumar JP, Ready DF (1995) Rhodopsin plays an essential structural role in Drosophila photoreceptor development. Development 121:4359-4370.

Luo L, Callaway EM, Svoboda K (2008) Genetic dissection of neural circuits. Neuron 57:634-660.

MacIntosh S (1996) Membrane recycling at photoreceptor synapses of the temperature-sensitive Drosophila melanogaster mutant shibire ${ }^{\mathrm{ts} 1}$. MSc thesis, Dalhousie University.

Maier O, Knoblich M, Westermann P (1996) Dynamin II binds to the transGolgi network. Biochem Biophys Res Commun 223:229-233.

Meinertzhagen IA (1996) Ultrastructure and quantification of synapses in the insect nervous system. J Neurosci Methods 69:59-73.

Meinertzhagen IA, O’Neil SD (1991) Synaptic organization of columnar 
elements in the lamina of the wild type in Drosophila melanogaster. J Comp Neurol 305:232-263.

O’Tousa JE, Baehr W, Martin RL, Hirsh J, Pak WL, Appleburg ML (1985) The Drosophila ninaE gene encodes an opsin. Cell 40:839-850.

Nikolaev A, Zheng L, Wardill TJ, O’Kane CJ, de Polavieja GG, Juusola M (2009) Network adaptation improves temporal representation of naturalistic stimuli in Drosophila eye: II mechanisms. PLoS One 4:e4306.

Palay SL, Sotelo C, Peters A, Orkand PM (1968) Axon hillock and initial segment. J Cell Biol 38:193-201.

Pantazis A, Segaran A, Liu CH, Nikolaev A, Rister J, Thum AS, Roeder T, Semenov E, Juusola M, Hardie RC (2008) Distinct roles for two histamine receptors ( $h c l A$ and $h c l B$ ) at the Drosophila photoreceptor synapse. J Neurosci 28:7250-7259.

Praefcke GJ, McMahon HT (2004) The dynamin superfamily: universal membrane tubulation and fission molecules? Nat Rev Mol Cell Biol 5:133-147.

Pucadyil TJ, Schmid SL (2008) Real-time visualization of dynamincatalyzed membrane fission and vesicle release. Cell 135:1263-1275.

Rister J, Pauls D, Schnell B, Ting CY, Lee CH, Sinakevitch I, Morante J, Strausfeld NJ, Ito K, Heisenberg M (2007) Dissection of the peripheral motion channel in the visual system of Drosophila melanogaster. Neuron 56:155-170.

Sarthy PV (1991) Histamine: a neurotransmitter candidate for Drosophila photoreceptors. J Neurochem 57:1757-1768.

Satoh AK, Ready DF (2005) Arrestin1 mediates light-dependent rhodopsin endocytosis and cell survival. Curr Biol 15:1722-1733.

Scott CW, Klika AB, Lo MM, Norris TE, Caputo CB (1992) Tau protein induces bundling of microtubules in vitro: comparison of different Tau isoforms and a Tau protein fragment. J Neurosci Res 33:19-29.

Shpetner HS, Vallee RB (1989) Identification of dynamin, a novel mechanochemical enzyme that mediates interactions between microtubules. Cell 59:421-432.

Stark WS, Sapp R, Schilly D (1988) Rhabdomere turnover and rhodopsin cycle: maintenance of retinula cells in Drosophila melanogaster. J Neurocytol 17:499-509.

Sun X (1998) Long-term action of shibire ${ }^{t s 1}$ in photoreceptor terminals. MSc thesis, Dalhousie University.

Tanabe K, Takei K (2009) Dynamic instability of microtubules requires dynamin 2 and is impaired in a Charcot-Marie-Tooth mutant. J Cell Biol 185:939-948.
Toh Y (1985) Structure of campaniform sensilla on the haltere of Drosophila prepared by cryofixation. J Ultrastruct Res 93:92-100.

Uusitalo RO, Juusola M, Weckström M (1995a) Graded responses and spiking properties of identified first-order visual interneurons of the fly compound eye. J Neurophysiol 73:1782-1792.

Uusitalo RO, Juusola M, Kouvalainen E, Weckström M (1995b) Tonic transmitter release in a graded potential synapse. J Neurophysiol 74: $470-473$.

Vähäsöyrinki M, Niven JE, Hardie RC, Weckström M, Juusola M (2006) Robustness of neural coding in Drosophila photoreceptors in the absence of slow delayed rectifier K+ channels. J Neurosci 26:2652-2660.

Vallee RB (1992) Dynamin: motor protein or regulatory GTPase. J Muscle Res Cell Motil 13:493-496.

van der Bliek AM, Meyerowitz EM (1991) Dynamin-like protein encoded by the Drosophila shibire gene associated with vesicular traffic. Nature 351:411-414.

van Hateren JH (1992) Theoretical predictions of spatiotemporal receptive fields of fly LMCs, and experimental validation. J Comp Physiol A Sens Neural Behav Physiol 171:157-170.

Wang T, Montell C (2007) Phototransduction and retinal degeneration in Drosophila. Pflugers Arch 454:821-847.

Westrum LE, Gray EG (1976) Microtubules and membrane specializations. Brain Res 105:547-550.

Yasuhara JC, Baumann O, Takeyasu K (2000) Localization of Na/K-ATPase in developing and adult Drosophila melanogaster photoreceptor. Cell Tissue Res 300:239-249.

Yoon Y, Pitts KR, Dahan S, McNiven MA (1998) A novel dynamin-like protein associates with cytoplasmic vesicles and tubules of the endoplasmic reticulum in mammalian cells. J Cell Biol 140:779-793.

Yu T, Fox RJ, Burwell LS, Yoon Y (2005) Regulation of mitochondrial fission and apoptosis by the mitochondrial outer membrane protein hFisl. J Cell Sci 118:4141-4151.

Zheng L, de Polavieja GG, Wolfram V, Asyali MH, Hardie RC, Juusola M (2006) Feedback network controls photoreceptor output at the layer of first visual synapses in Drosophila. J Gen Physiol 127:495-510.

Zheng L, Nikolaev A, Wardill TJ, O’Kane CJ, de Polavieja GG, Juusola M (2009) Network adaptation improves temporal representation of naturalistic stimuli in Drosophila eye: I dynamics. PLoS One 4:e4307. 